\title{
Investigation of the impact of the configuration of exhaust after-treatment system for diesel engines
}

\author{
Chung Ting Lao ${ }^{\mathrm{a}}$, Jethro Akroyd ${ }^{\mathrm{a}, \mathrm{b}}$, Nickolas Eaves ${ }^{\mathrm{a}, \mathrm{d}}$, Alastair Smith \\ Neal Morgan ${ }^{\mathrm{e}}$, Daniel Nurkowski ${ }^{\mathrm{f}}$, Amit Bhave ${ }^{\mathrm{f}}$, Markus Kraft ${ }^{\mathrm{a}, \mathrm{b}, \mathrm{c}, *}$ \\ ${ }^{a}$ Department of Chemical Engineering and Biotechnology, University of Cambridge, West \\ Cambridge Site, Philippa Fawcett Drive, Cambridge CB3 0AS, United Kingdom \\ ${ }^{b}$ CARES, Cambridge Centre for Advanced Research and Education in Singapore, 1 \\ Create Way, CREATE Tower, \#05-05, Singapore, 138602 \\ ${ }^{c}$ School of Chemical and Biomedical Engineering, Nanyang Technological University, 62 \\ Nanyang Drive, Singapore, 637459 \\ ${ }^{d}$ Mechanical, Automotive and Materials Engineering, University of Windsor, 401 Sunset \\ Avenue, Windsor, ON, N9B 3P4, Canada \\ ${ }^{e}$ Shell Centre, York Road, London, SE1 7NA, United Kingdom \\ ${ }^{f} C M C L$ Innovations, Sheraton House, Cambridge, CB3 0AX, United Kingdom
}

\section{Abstract}

Exhaust After-Treatment (EAT) systems are necessary for automotive powertrains to meet stringent emission standards. Computational modelling has been applied to aid designing EAT systems. Models with global kinetic mechanisms are often used in practice, but they cannot accurately predict the behaviour of after-treatment devices under a wide range of conditions. In this study, a numerical EAT model with rigorous treatment of the catalytic chemistry is proposed to investigate the impact of the configuration of individual devices in the EAT system; one of the key design decisions. The performance of the proposed model is first critically assessed against experimental and simulation data from the literature before being applied

\footnotetext{
* Corresponding author

Email address: mk306@cam.ac.uk (Markus Kraft)
} 
to design a multi-device EAT system for a diesel engine. The target EAT system is composed of a diesel oxidation catalyst (DOC), an ammonia-based selective catalytic reduction $\left(\mathrm{NH}_{3}-\mathrm{SCR}\right)$ device and a diesel particulate filter (DPF). The steady state behaviour of various EAT designs under operating conditions across the engine map are examined. The DOC-DPF-SCR layout is found to be more beneficial than the alternative DOC-SCR-DPF for the specific engine studied. Furthermore, the DPF-front system is more robust with respect to changes in emission regulations. Flux analysis is applied to study the chemical interaction in the SCR and explain the disadvantage of the SCR-front system. In addition, it is demonstrated in the study that future catalyst investigations should consider more realistic feed compositions. Keywords: Exhaust After-Treatment (EAT), Diesel oxidation catalyst (DOC), Ammonia-based Selective Catalytic Reduction $\left(\mathrm{NH}_{3}-\mathrm{SCR}\right)$, Diesel Particulate Filter (DPF), Numerical model

\section{Introduction}

Internal Combustion Engines (ICEs) are widely used to provide power for vehicles [1]. In 2018, vehicles with ICEs powered by petrol and diesel made up over $90 \%$ of the new passenger car registrations in the European Union (EU) [2], and in particular, $96 \%$ of heavy-duty engines in EU are powered by diesel [3]. However, emissions from ICE containing carbon monoxide (CO) [4], unburnt hydrocarbon $(\mathrm{uHC})[5]$, nitrogen oxides (NOx) [6] and particulate matter (PM) [7] which can cause adverse impacts on human health and the environment. Correspondingly, governing bodies have set legal limits on ICE emissions that manufacturers must meet. 
Since tailpipe emissions depend on the operating conditions of the ICE, the engine "test cycle" must be clearly defined such that the emission measurements are repeatable [10]. However, it has been found that emission measurements using simple test cycles such the New European Driving $\mathrm{Cy}-$ cle (NEDC) are not representative of the actual on-road emissions [11]. And as a result, more realistic test cycles such as the Worldwide Harmonized Light Vehicles Test Cycle (WLTC) have been introduced [11]. In addition, Real Driving Emission (RDE) testing will be implemented, in which tailpipe emissions are measured when the vehicle is operating on-road [6].

Exhaust After-Treatment (EAT) is an important part of emission control of ICEs. Other emission control technologies, such as exhaust gas recirculation (EGR) and alternative fuel formulations, have also been applied by manufacturers to meet the increasingly stringent emission standards [12, 13]. In contrast to other emission control technologies, the EAT system has a smaller impact on the in-cylinder combustion. It is placed between the engine cylinders and the tailpipe in a vehicle where it reduces the regulated substances in the engine-out exhaust.

Typical EAT systems for diesel engines are composed of three individual devices [14]. Diesel EAT systems usually contain two Flow-Through Monoliths (FTMs) with a catalytic coating on the channel walls for the mitigation of gaseous pollutants. The structure of a typical FTM is shown in Fig. 1(a). The purpose of the Diesel Oxidation Catalyst (DOC) is to oxidise CO and uHC to form $\mathrm{CO}_{2}$ and $\mathrm{H}_{2} \mathrm{O}$ [15]. In addition to the DOC, a separate FTM is required for NOx control. The reduction of NOx to nitrogen $\left(\mathrm{N}_{2}\right)$ is difficult due to the high level of oxygen $\left(\mathrm{O}_{2}\right)$ in diesel exhaust [16]. Two technologies 
are commonly applied to reduce NOx emission, namely the Lean NOx Trap (LNT) and the Selective Catalytic Reduction (SCR) device. In this work, we focus on the SCR technology since it is the preferred deNOx technology for heavy-duty applications $[17,18]$. The SCR is able to reduce $\mathrm{NOx}$ to $\mathrm{N}_{2}$ at high oxygen levels with the aid of an additional reductant. The most popular of which is ammonia $\left(\mathrm{NH}_{3}\right)$ [19], stored in the form of urea solution. During operation, urea is injected into the exhaust flow and $\mathrm{NH}_{3}$ is formed from the decomposition of urea [15]. SCR with alternative reductants, for example hydrocarbon [20] and CO [21], are also possible.

Whilst catalytic FTMs are effective for controlling toxic gaseous emissions, Diesel Particulate Filters (DPFs) are required to control particulate emissions. DPFs have a Wall-Flow Monolith (WFM) structure as shown in Fig. 1(b). As opposed to having open channels like the FTM, the ends of channels in a WFM are alternately plugged. Particulates in the exhaust accumulate in the porous wall between channels when exhaust flows through the device. The backpressure in the DPF will increase during operation due to accumulation of particles in the device. This leads to worse in-cylinder combustion performance, and hence trapped particles are removed by "regeneration", which is the combustion of the carbonaceous part of trapped particles.

Regeneration strategies can be categorised as either "active" or "passive". During active regeneration, the temperature of the DPF is increased temporarily by the means of altering engine operation, external fuel injection [22] or microwave heating [23]. Trapped particles are then be burnt by $\mathrm{O}_{2}$ at above $500^{\circ} \mathrm{C}[24]$. For passive regeneration, trapped particles are oxidised by 


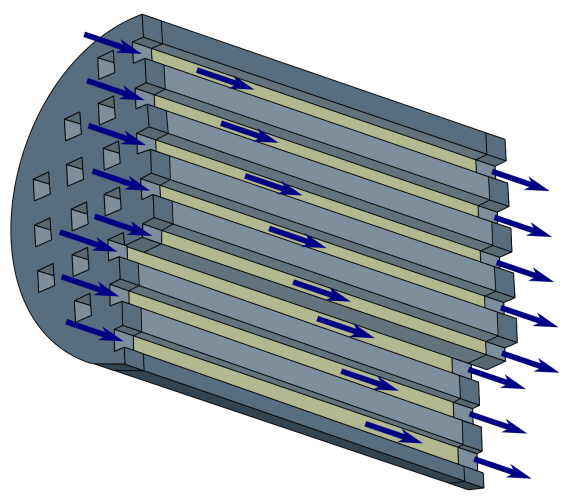

(a) Flow Through Monolith (FTM).

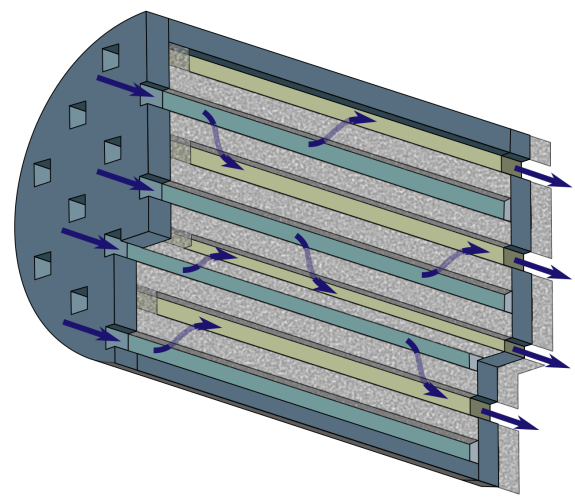

(b) Wall Flow Monolith (WFM).

Figure 1: The structures of a Flow Through Monolith (FTM) and a Wall Flow Monolith (WFM) are shown.

$\mathrm{NO}_{2}$, a much more powerful oxidant than $\mathrm{O}_{2}$. The reaction is spontaneous at typical diesel exhaust temperatures $\left(300^{\circ} \mathrm{C}[25]\right)$. A balance between filtration and passive regeneration may be reached without an additional heat source and hence passive regeneration is more favourable than active regeneration strategies since it has a lower associated fuel penalty [26]. However, passive regeneration may not be viable at all operating conditions and hence active regeneration remain an essential part of DPF control stretagies [27].

Since more than one EAT device is required, there are several possible combinations of individual devices in the EAT system. It is important to understand the synergistic and competitive interactions between EAT devices in order to choose the optimal configuration for a certain engine. The DOC is usually the first device in the system due to its beneficial impact on downstream devices. First of all, the thermal energy released from exothermic reactions occurring inside the DOC can warm up downstream devices. This 
can help reduce tailpipe emission during cold-start of engines due to catalyst inactivity at low temperature [28]. Furthermore, the DOC is able to convert $\mathrm{NO}$ to $\mathrm{NO}_{2}$ as well as oxidising $\mathrm{CO}$ and $\mathrm{uHC}$ [29]. $\mathrm{NO}_{2}$ generated from the DOC can assist passive regeneration in the DPF. The deNOx performance in the SCR can be improved if the $\mathrm{NO}_{2} / \mathrm{NOx}$ ratio is increased [30]. The DOC is also used to initiate active regeneration in the DPF, for example raising the temperature of exhaust by oxidising injected fuel [31].

On the other hand, the interactions between the DPF and the SCR are mainly competitive. If the DPF is placed in front of the SCR ("DPF-front"), the SCR will warm up more slowly during cold-start period as the DPF acts as a heat sink [32]. Passive regeneration in the DPF would consume $\mathrm{NO}_{2}$ in the exhaust, preventing maximum deNOx performance in the downstream SCR. Furthermore, the downstream SCR is vulnerable to the heat generated from active regeneration in the DPF. In spite of these negative influences on SCR performance, the upstream DPF can reduce particle fouling on the wall of the downstream SCR [33]. Depending on the economic analysis, it may be preferable to have a "SCR-front" system, where the performance of the SCR is better, at the expense of suppressing passive regeneration in the downstream DPF, resulting in increased fuel consumption [14].

Given the complexity of the processes and interactions within EAT system, computational models are widely used to study and optimise the designs and control strategies of EAT systems [15, 34, 35]. The performance of the EAT system is affected by numerous phenomena, including gas flow, heat and mass transfer, chemical reaction as well as particle filtration. Furthermore, each channel in a EAT device may behave differently depending on the 
inlet conditions and the relative positions of the channels inside the monolith. Depending on the purpose of the model, various simplifications of the model may be made to lower the computing cost while maintaining sufficient accuracy [36]. For example, the overall behaviour of a EAT device may be described by simulating a single representative channel with reasonable accuracy instead of simulating every channel in the monolith [37]. This is the most common approach for investigations focusing on the catalytic chemistry since the reaction kinetics is unaffected by the monolith structure [36].

One of the difficulties in EAT modelling arises from the complex reaction mechanisms of the catalyst. Simple "global kinetic" mechanisms with semi-empirical reaction rate expressions (based on work of Voltz et al. [38] for example) are often used. However they are rarely able to describe the change in catalyst behaviour under different operating conditions where the inlet composition changes significantly [39]. The global kinetic approach is also unable to describe the composition profile of species adsorbed on the catalyst which can have significant impact [40]. The capability of handling detailed microkinetic mechanisms based on elementary reactions is desirable for after-treatment models because of increasingly stringent emission testing procedures and emission standards. Furthermore, such models can allows better understanding of the intrinsic kinetics of the catalyst, which is especially useful for investigation of new catalyst formulations for the nextgeneration after-treatment technology.

This paper aims to propose a computational EAT model that allows a rigorous treatment for the catalytic chemistry unlike black-box models provided by most manufacturers [15]. Such a model can offer more insight into 
the chemical phenomena in the EAT system, and shed light on the interaction between individual devices. This work focuses on the steady state of the after-treatment system for three main reasons. First, steady state operation provides a good indication of sufficient passive regeneration, an important phenomena for multi-device EAT system for diesel engines. Second, heavyduty engines are subject to both transient and steady state tests. Examples from the EU regulations include the European Stationary Cycle (ESC) for heavy-duty road vehicles and the Non-Road Steady Cycle (NRSC) for nonroad engines [41]. Third, EAT systems are usually designed to pass a specific emission test cycle, which may not adequately consider all operating conditions occurring under actual usage. In this work, the proposed model is applied to study the chemical interaction and performance of EAT systems at different operating points across the engine map.

The rest of this paper is structured as follows: The governing equations of the proposed model and the numerical methods used are described in Section 2. The proposed model is then applied to simulate individual EAT devices. The results are compared with experimental and simulation data from the literature in Section 3. After that, the proposed model is integrated with a virtual engine cylinder simulation software in Section 4 to investigate the advantages and disadvantages of DPF-front and SCR-front systems via a case study of a heavy-duty diesel engine. Finally, element flux analysis is applied in Section 4.2.3 to study the chemical phenomena in the EAT system. 


\section{Model description}

This section is split into two parts. The first part describes the governing equations of the after-treatment model. The second part describes the coupling between the engine in-cylinder combustion model and the aftertreatment model.

\subsection{Governing equations}

The model used in this work is a modified version of the WFM model described in detail by Lao et al. [42]. The key equations used in this work is summarised below.

The single channel approach is applied in this study to simulate EAT devices. It assumes that all channels in the monolith have the same behaviour. A single FTM channel is described by a two-layer one-dimensional model, where the channel and the catalytic washcoat are considered as single layers discretised in the axial direction respectively. The spatial representation of a FTM in the model is shown in Fig. 2(a). For WFM, a pair of inlet and outlet channels, as well as the porous wall in between, are modelled [42]. The channels are discretised in the axial direction. The porous wall is discretised in the through-wall direction in addition to the axial direction. The spatial representation of a WFM in the model is shown in Fig. 2(b). Ideal gas behaviour has been assumed for the gas phase mixture.

The gas flows along the channels of FTMs and WFMs are governed by the Bernoulli's equation, whereas the gas flows in the through-wall direction across the particle cake layer and the porous wall in WFMs are governed by Darcy's Law. The variation of gas pressure along channels and across porous 


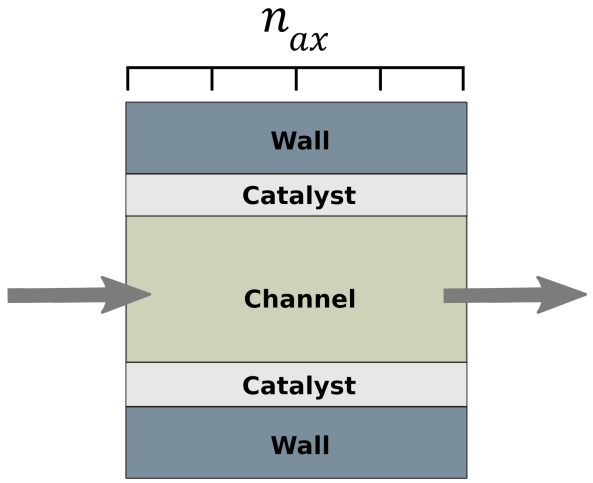

(a) Flow Through Monolith (FTM).

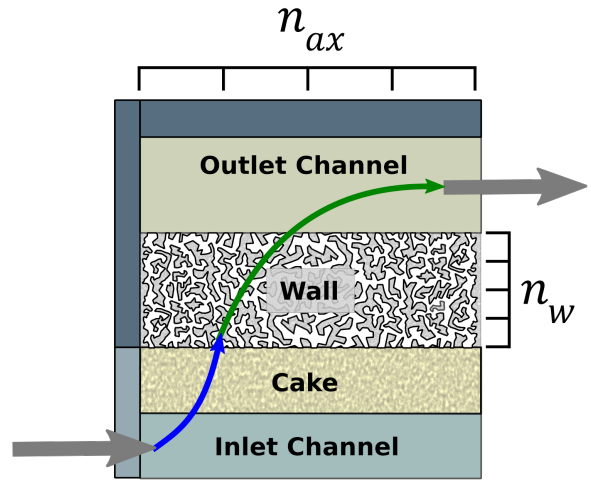

(b) Wall Flow Monolith (WFM).

Figure 2: The spatial representations of a FTM and a WFM in the model.

medium are described by eq. (1) and (2) respectively [42]:

$$
\begin{gathered}
P_{\text {in }}+\frac{1}{2} \rho_{\text {in }} u_{\text {in }}^{2}=P_{\text {out }}+\frac{1}{2} \rho_{\text {out }} u_{\text {out }}^{2}+\frac{F \mu L_{\mathrm{ch}}}{D^{2}} u_{\text {out }}, \\
P_{\text {in }}-P_{\text {out }}=\frac{\mu v L_{\text {porous medium }}}{\kappa},
\end{gathered}
$$

where $P$ is pressure, $\rho$ is gas mass density, $u$ is gas flow velocity in a channel, $F$ is a friction factor ( $=28.454$ for square channel [43]), $\mu$ is dynamic viscosity, $L$ is the distance between volume elements, $D$ is the side length of the cross-section of a square channel, $v$ is the gas flow velocity across porous media and $\kappa$ is the permeability of the porous medium. The subscripts "in" and "out" denote adjacent upstream and downstream volume elements respectively.

The model proposed by this work can describe the composition of the gas phase and the "surface" phase i.e. adsorbed species on the reactive surface of the catalyst. The composition of the gas phase is affected by the gas flow 
and chemical reactions. The governing equation of the gas phase species is shown below [42]:

$$
\begin{aligned}
\frac{\mathrm{d} n_{\gamma, i}}{\mathrm{~d} t} & =\sum_{j \in S_{\mathrm{in}, i}} \frac{\dot{m}_{j} Y_{\gamma, \mathrm{in}, j}}{M_{\gamma}}-\sum_{j \in S_{\mathrm{out}, i}} \frac{\dot{m}_{j} Y_{\gamma, i}}{M_{\gamma}}+V_{i} \sum_{w=1}^{W} \nu_{\gamma, w} r_{w, i} \\
& +4 L_{\mathrm{ch}} S h \rho_{\mathrm{m}, i} D_{\mathrm{m}, \gamma, i} \Delta x_{\mathrm{ch}-\mathrm{wc}, \gamma, i}
\end{aligned}
$$

where $n$ is the number of mole of a gas species, $\dot{m}$ is the gas mass flow rate, $Y$ is the mass fraction, $M$ is the molar mass of a gas species, $V$ is the volume of a volume element, $\nu$ is the stoichiometric coefficient of a species in a reaction and $r$ is the rate of reaction, $\gamma$ is the index of gas phase species, $i$ is the index of volume elements, $j$ is the index of connection between two volume elements which allows gas flow, $w$ is the index of reactions, $S_{\mathrm{in}, i}$ is the set of all inflow connections to volume element $i, S_{\text {out }, i}$ is the set of all outflow connections to volume element $i, W$ is the total number of reactions, $S h$ is the Sherwood number for convection between channel and the washcoat, $\rho_{\mathrm{m}, i}$ is the molar density in volume element $i, D_{\mathrm{m}, \gamma, i}$ is the diffusivity of species $\gamma$ in volume element $i$ and $\Delta x_{\mathrm{ch}-\mathrm{wc}, \gamma, i}$ is the difference in mole fraction of species $\gamma$ between volume element $i$ and its corresponding channel/washcoat volume element. The Sherwood number used in this work is 3 assuming fully developed laminar flow in the channels [44]. Diffusivities of gas phase species are calculated using transport data from GRI-Mech 3.0 [45].

The composition of surface species is described by eq. (4) below:

$$
\frac{\mathrm{d} n_{\beta, i}}{\mathrm{~d} t}=V_{i} \sum_{w=1}^{W} \nu_{\beta, w} r_{w, i}
$$


where $\beta$ is the index of surface phase species. Adsorption and desorption of species are described as chemical reactions which is a common practice for EAT modelling [for example 46, 44]. A micro-kinetic approach is used for the treatment of the chemistry to allow the application of a detailed kinetic mechanism. The rate of a reaction is based on an Arrhenius-type equation, with capability of considering user-specified reaction order and coverage dependency of activation energy [47]. The rate of a reaction $r$ is calculated as follows:

$$
\begin{gathered}
r_{w, i}=\eta k_{w, i} \prod_{\gamma=1}^{\Gamma} c_{\gamma, i}^{X_{\gamma, w}} \prod_{\beta=1}^{\Psi}\left(\frac{S_{i}}{V_{i}} \zeta_{\beta, i}\right)^{X_{\beta, w}}, \\
k_{w, i}=A_{w} T_{i}^{B_{w}} \exp \left(-\frac{E_{w}}{R T_{i}}\right) \prod_{\beta=1}^{\Psi} \exp \left(\frac{-\sigma_{\beta, w} \theta_{\beta, i}}{R T_{i}}\right),
\end{gathered}
$$

where $c_{\gamma, i}$ is the molar concentration of gas species, $\Gamma$ is the total number of gas phase species, $X$ is the reaction order of a gas species, $S$ is the reactive surface area in a volume element, $\zeta$ is the surface concentration of a surface species, $\Psi$ is the total number of surface phase species, $A$ is the preexponential constant, $B$ is the temperature exponent and $E$ is the activation energy of a reaction. An effectiveness factor ( $\eta$ in eq. (5)) is applied to describe the effect of coupled reaction-diffusion in the catalytic washcoat. The effectiveness factor is calculated as described by Mladenov et al. [48]. The coverage dependency is represented by the product of exponentials on the right hand side of eq. (6) where $\sigma$ and $\theta$ are a coverage dependent parameter and site fraction of a surface species respectively.

A sectional method is applied to numerically solve the particle size distribution in after-treatment devices [42]. The number density of trapped 
particles $N_{z, i}$ of size class $z$ in the porous wall volume element $i$ is governed by the following equation:

$$
\frac{\mathrm{d} N_{z, i}}{\mathrm{~d} t}=Q_{z, i} \dot{N}_{z, \text { in }}+\left(k_{\mathrm{AR}}\left[\mathrm{O}_{2}\right]+k_{\mathrm{PR}}\left[\mathrm{NO}_{2}\right]\right)\left(\pi d_{\mathrm{p}, z}^{2} N_{z, i}\right)
$$

where $Q_{z, i}$ is the filtration efficiency of particles of size class $z, \dot{N}_{z \text {,in }}$ is the inlet flow rate of particle number density and $d_{\mathrm{p}, z}$ is the diameter of particle in size class z. $Q_{z, i}$ is calculated using the classic unit collector model [49]. It is described in detail elsewhere [42, Section 2.2]. The extended features developed by Lao et al. [42] are not included in this work since those features are applied to describe the transient behaviour of active regenerating DPFs, which is beyond the scope of this work.

The model used in this work considers passive regeneration by $\mathrm{NO}_{2}$ in addition to thermal active regeneration by $\mathrm{O}_{2}$. Alternative catalysed regeneration pathways due to fuel additives [50] or embedded catalysts within the $\mathrm{DPF}$ are not considered in this work. $k_{\mathrm{AR}}$ and $k_{\mathrm{PR}}$ are the rate constants for active and passive regeneration reactions. The expressions for the rate constants are as described by Kandylas and Koltsakis [29].. The following regeneration reactions are considered in the model:

$$
\begin{gathered}
\mathrm{C}+\alpha_{1} \mathrm{O}_{2} \rightarrow\left(2 \alpha_{1}-1\right) \mathrm{CO}_{2}+\left(2-2 \alpha_{1}\right) \mathrm{CO}, \\
\mathrm{C}+\alpha_{2} \mathrm{NO}_{2} \rightarrow \alpha_{2} \mathrm{NO}+\left(\alpha_{2}-1\right) \mathrm{CO}_{2}+\left(2-\alpha_{2}\right) \mathrm{CO},
\end{gathered}
$$

where $\alpha_{1}$ and $\alpha_{2}$ are stoichiometric coefficients of the regeneration reactions. Different literatures $[43,49,51,52]$ suggest different values of $\alpha_{1}$ and 
$\alpha_{2}$ and their temperature dependences. In this study, $\alpha_{1}$ and $\alpha_{2}$ take constant values of 0.8 and 1.8 respectively, within the possible range suggested in literature [29].

The thermal behaviour of the EAT system is neglected in the model used in this work. This is justified for two reasons: First, the heat of reaction in SCR is usually negligible [44]. It is found by Schejbal et al. [53] that the same applies to the DOC and passively regenerating DPF. As a result, no heat generation is expected at steady state. Second, heat loss to the environment is limited by the presence of insulation around EAT devices. Whilst heat loss to

the environment can be influential to the time required for the EAT system to warm up and to eventually reach steady state, it would have negligible impact on the final steady state temperature achieved in insulated EAT devices. Therefore the heat balance equation of the EAT system is omitted in this model assuming insulations are appropriately designed to minimise heat loss of the EAT system. This is deemed acceptable under steady state operation where there is no occurrence of highly exothermic uncontrolled regeneration [54]. As a result, the temperature of the EAT system is that of the inlet flow at steady state.

\subsection{Coupling with engine model}

The Stochastic Reactor Model (SRM) Engine Suite [55] is used to specify the inlet boundary conditions to the EAT system. The SRM Engine Suite can predict the cylinder-out mass flow rate, gas composition and temperature of the exhaust using a Probability Density Function (PDF) based model [56]. It has been shown to be a computationally efficient tool for simulating different types of internal combustion engines including gasoline engines [59], 
homogeneous charge compression ignition engines [62], natural gas engines [57] and predicting gaseous [58] and particulate emissions [66].

Whilst the mass flow rate and gas composition should remain unchanged from the cylinder to the inlet of the EAT system, there is significant heat loss when the exhaust passes from engine cylinders to the EAT system through the turbocharger and pipings. Gao et al. [68] performed an energy analysis on a heavy-duty diesel engine with turbocharger. The ratio between the enthalpy of the post-turbine exhaust and the enthalpy of the injected fuel was reported for a range of output power and engine speed [68, Fig. $9 \& 15]$.

Assuming that the engine considered in this work exhibits the same behaviour, the enthalpy ratio can be used to estimate the temperature of the exhaust at the exit of the turbine. This assumption is justified on the basis of the similarity between both engines $(8.6 \mathrm{~L}, 260 \mathrm{~kW}$ rated power, $2100 \mathrm{rpm}$ maximum speed studied by Gao et al. [68] versus 7 L, $205 \mathrm{~kW}$ rated power, $2200 \mathrm{rpm}$ maximum speed studied here). The output power, engine speed and the amount of heat in the injected fuel are provided by the SRM Engine Suite and can be used to interpolate an enthalpy ratio from experimental data reported by Gao et al. [68]. The enthalpy of the post-turbine exhaust and the exhaust temperature at the turbine exit can then be calculated since the engine-out composition and the mass flow rate are given by the SRM Engine Suite.

In this work, the engine is assumed to be operating at steady state. Thus the boundary conditions of the EAT system does not vary with time. The modelling equations of EAT system (eq. (1)-(7)) are integrated with time until either steady state is reached or the system ceases to function correctly 
due to DPF clogging.

\section{Model assessment}

In this section, the proposed EAT model is applied to simulate individual EAT devices including a DOC, SCR and DPF. The results of the simulations are compared with experimental and simulation data from literature.

\subsection{Diesel Oxidation Catalyst (DOC)}

The main functionality of the DOC is to completely oxidise $\mathrm{CO}$ and $\mathrm{uHC}$. It is also capable of promoting NO oxidation subject to thermodynamic constraints. The overall reactions are shown below, where $\mathrm{uHC}$ is represented by $\mathrm{C}_{3} \mathrm{H}_{6}$, a common choice in literature modelling studies $[46,48,71]$ :

$$
\begin{gathered}
2 \mathrm{C}_{3} \mathrm{H}_{6}+9 \mathrm{O}_{2} \stackrel{\mathrm{Pt}}{\longrightarrow} 6 \mathrm{CO}_{2}+6 \mathrm{H}_{2} \mathrm{O} \\
2 \mathrm{CO}+\mathrm{O}_{2} \stackrel{\mathrm{Pt}}{\longrightarrow} 2 \mathrm{CO}_{2} \\
2 \mathrm{NO}+\mathrm{O}_{2} \stackrel{\mathrm{Pt}}{\rightleftharpoons} 2 \mathrm{NO}_{2}
\end{gathered}
$$

The proposed model is applied to simulate a platinum catalyst experimentally studied by Koop and Deutschmann [46]. They developed a chemical mechanism to describe the redox reactions between platinum and exhaust gas species. They evaluated the performance of the chemical mechanism by simulating the conversion of NO of a platinum catalyst at three different temperatures and two inlet conditions, namely "lean" $\left(12 \% \mathrm{O}_{2}\right)$ and "rich" 
$\left(0.9 \% \mathrm{O}_{2}\right)$. They showed good agreement between their simulation and their experimental results.
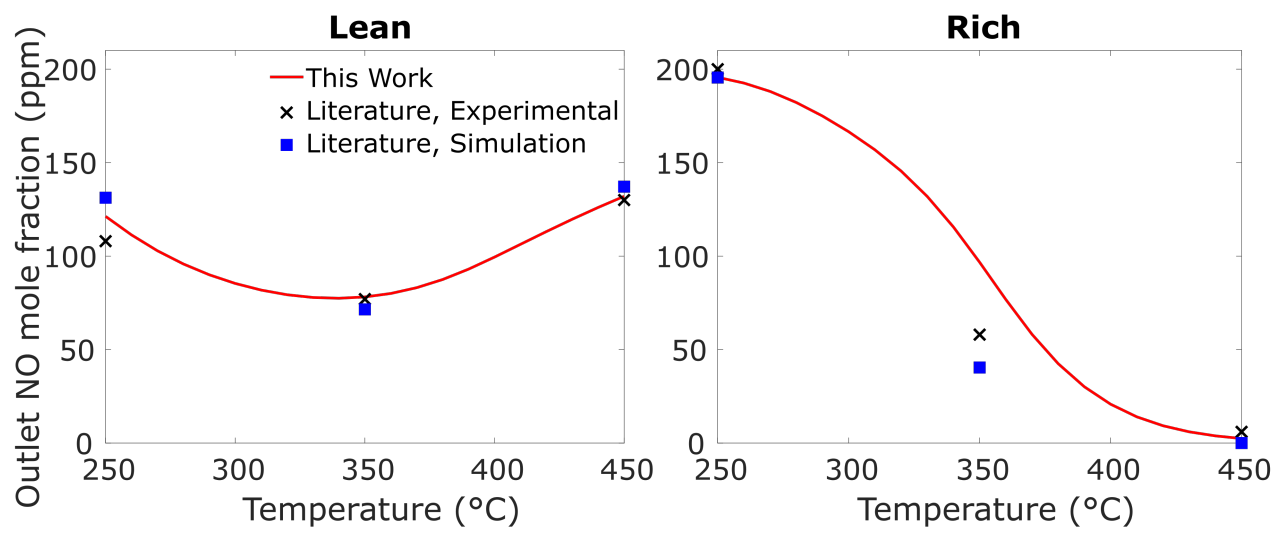

Figure 3: Comparison of model prediction by the proposed model and literature model [46]. The outlet concentrations of NO under lean and rich conditions agreed qualitatively.

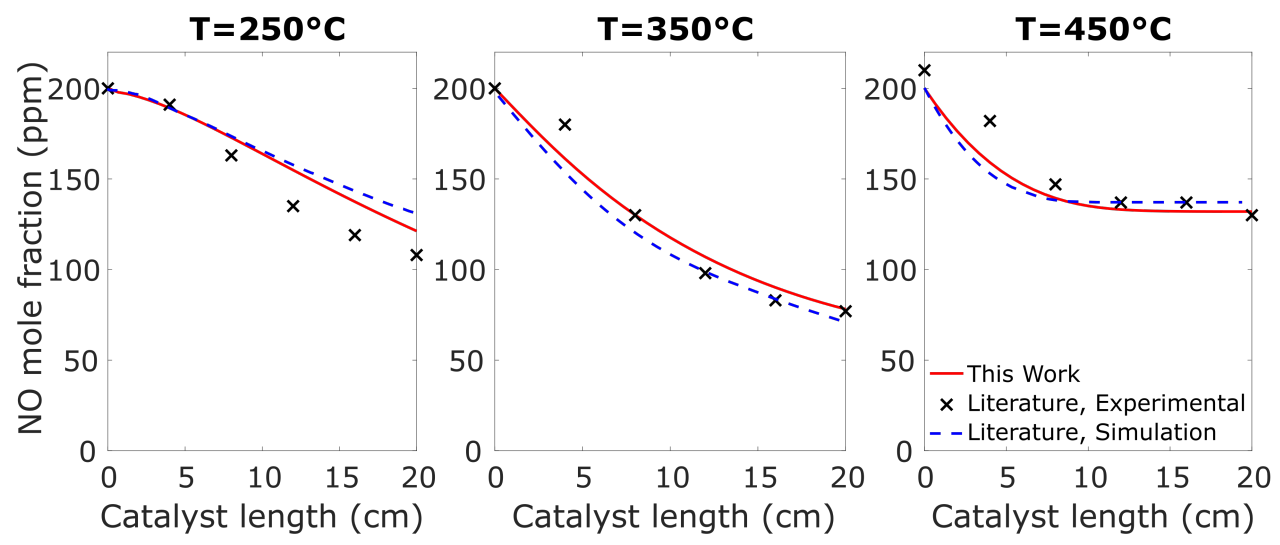

Figure 4: Comparison of model prediction by the proposed model and literature results [46]. The proposed model is able to describe the axial NO profile along the DOC channel under lean conditions.

The performance of the proposed model is evaluated by simulating the same set of experiments using the same chemical mechanism. It should be 
noted there are significant differences between the proposed model and the model used by Koop and Deutschmann [46]. The main difference between the proposed model and the literature model is the treatment for convective mass transfer phenomena. The literature model considers the catalytic channel using a two-dimensional cylindrical coordinate. As a result, radial mass transfer from the bulk gas flow to the washcoat is solved directly. In the proposed model, the convective mass transfer is modelled using a constant Sherwood number approach [44]. NO is chosen to be the rate limiting species in the effectiveness factor model following the choice made by Koop and Deutschmann [46] duing the development of the mechanism. Other modelling parameters are identical to those used by Mladenov et al. [48].

The experimental measurements and simulations from the literature, as well as predicted outlet NO concentrations made by the proposed aftertreatment model are shown in Fig. 3. The axial profiles of NO with "lean" inlet are shown in Fig. 4.

The differences between the model predictions by the literature model and the proposed model can be attributed to the different treatments for the convective mass transfer between the bulk gas and the catalyst. The computational cost of the proposed model would be significantly lower than the literature model due to the one-dimensional axial coordinate description of the DOC channels, and therefore the trade-off with accuracy in the prediction is deemed acceptable.

\subsection{Selective Catalytic Reduction (SCR)}

The purpose of a $\mathrm{NH}_{3}$-SCR is to reduce $\mathrm{NOx}$ to $\mathrm{N}_{2}$ by $\mathrm{NH}_{3}$. There are three major reaction pathways, "standard-SCR" (eq. 13), "fast-SCR" (eq. 14) 
and " $\mathrm{NO}_{2}$-SCR" (eq. 15) [44]:

$$
\begin{gathered}
4 \mathrm{NO}+4 \mathrm{NH}_{3}+\mathrm{O}_{2} \stackrel{\text { cat. }}{\longrightarrow} 4 \mathrm{~N}_{2}+6 \mathrm{H}_{2} \mathrm{O} \\
\mathrm{NO}+\mathrm{NO}_{2}+2 \mathrm{NH}_{3} \stackrel{\text { cat. }}{\longrightarrow} 2 \mathrm{~N}_{2}+3 \mathrm{H}_{2} \mathrm{O} \\
6 \mathrm{NO}_{2}+8 \mathrm{NH}_{3} \stackrel{\text { cat. }}{\longrightarrow} 7 \mathrm{~N}_{2}+12 \mathrm{H}_{2} \mathrm{O}
\end{gathered}
$$

$\mathrm{NH}_{3}$-SCR catalyst formulations are usually based on either Vanadium or Iron/Copper zeolites [72]. As zeolites have better thermal resistance than Vanadium-based catalyst, they are suitable in both SCR-front and DPF-front layouts, whereas Vanadium-based catalyst are only suitable for SCR-front layout [14]. Therefore a Copper zeolite SCR catalyst is chosen for this study.

The chemical mechanism of the Cu-ZSM-5 catalyst developed by Olsson et al. [44] is used in this work. Olsson et al. [44] calibrated the reaction mechanism against various sets of the experimental data. One of the experiments investigated the effect of changing $\mathrm{NO}$-to- $\mathrm{NO}_{2}$ ratio at the inlet. The inlet concentration underwent step-changes at the time specified in Table 1. The concentrations of $\mathrm{NO}, \mathrm{NO}_{2}$ and $\mathrm{N}_{2} \mathrm{O}$ were measured at the outlet.

The proposed model was assessed by simulating the same experiment and comparing the model results with experimental measurements and model predictions made by Olsson et al. [44]. Olsson et al. [44] concluded that washcoat diffusion was negligible in this case and therefore the effectiveness factor model is not applied to SCR simulations. Experimental measurements and predicted concentrations of the literature model and the proposed model are shown in Fig. 5. 
Table 1: Inlet conditions used in the SCR experiment [44].

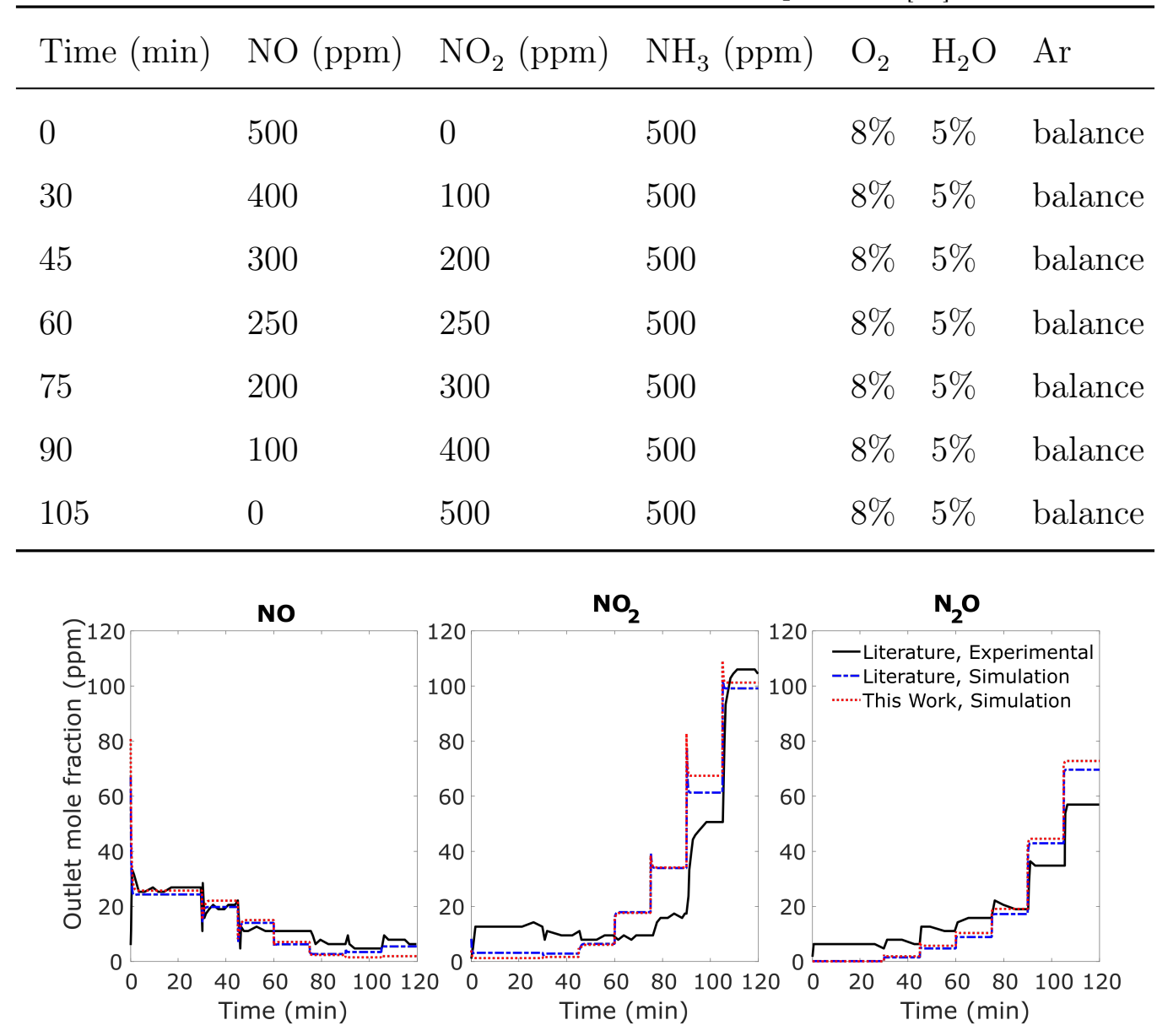

Figure 5: Comparison of model prediction of $\mathrm{NO}, \mathrm{NO}_{2}$ and $\mathrm{N}_{2} \mathrm{O}$ emission by the proposed model and literature results [44].

Qualitative agreements can be observed between the three sets of data. The differences between predictions by the literature model and the proposed model may be attributed to the different treatments of convective mass transfer. Whilst the formulations for convective mass transfer are equivalent, Olsson et al. [44] did not report the transport data used for calculations of 
diffusion coefficients of gas phase species. This may lead to slightly different gas phase composition within the porous catalytic washcoat and hence small differences in predicted NOx conversions.In conclusion, the combination of the chemical mechanism and the proposed model are shown to be able to capture the general trend of the change in NOx conversion, and therefore are sufficient for investigations on the impact of device configurations on overall EAT system design.

\subsection{Diesel Particulate Filter (DPF)}

It is important to ensure that the proposed model can simulate both the filtration and regeneration process of the DPF with sufficient accuracy. The ability of the proposed model to simulate the filtration behaviour of DPFs is checked against results by Zhang et al. [73] who simulated a DPF that had been studied experimentally by Suresh et al. [74]. The proposed model is applied to predict the change in pressure drop of the DPF as it collects particles, as the pressure drop of the DPF is commonly used in modelling studies to characterise the filtration behaviour [75]. In this work, it is assumed that the inlet particle diameter is $100 \mathrm{~nm}$ which is typical for diesel engines [76]. The capability of the DPF model to describe the impact of particles has been comprehensively investigated in previous work [42].

The results of experiment and simulations are shown in Fig. 6, where we can observe excellent agreements between the literature data and predictions by the proposed model. The following parameters have been calibrated: The particle packing density $=4.0 \mathrm{~kg} / \mathrm{m}^{3}$, the percolation constant $=0.918$, the porosity of the particle cake layer $=96 \%$ and the primary particle diameter of the particle cake layer $=27 \mathrm{~nm}$. The first two parameters determine when 
the DPF pressure drop transitions to linearly increasing with time and the latter two parameters determine the gradient of the linear phase.

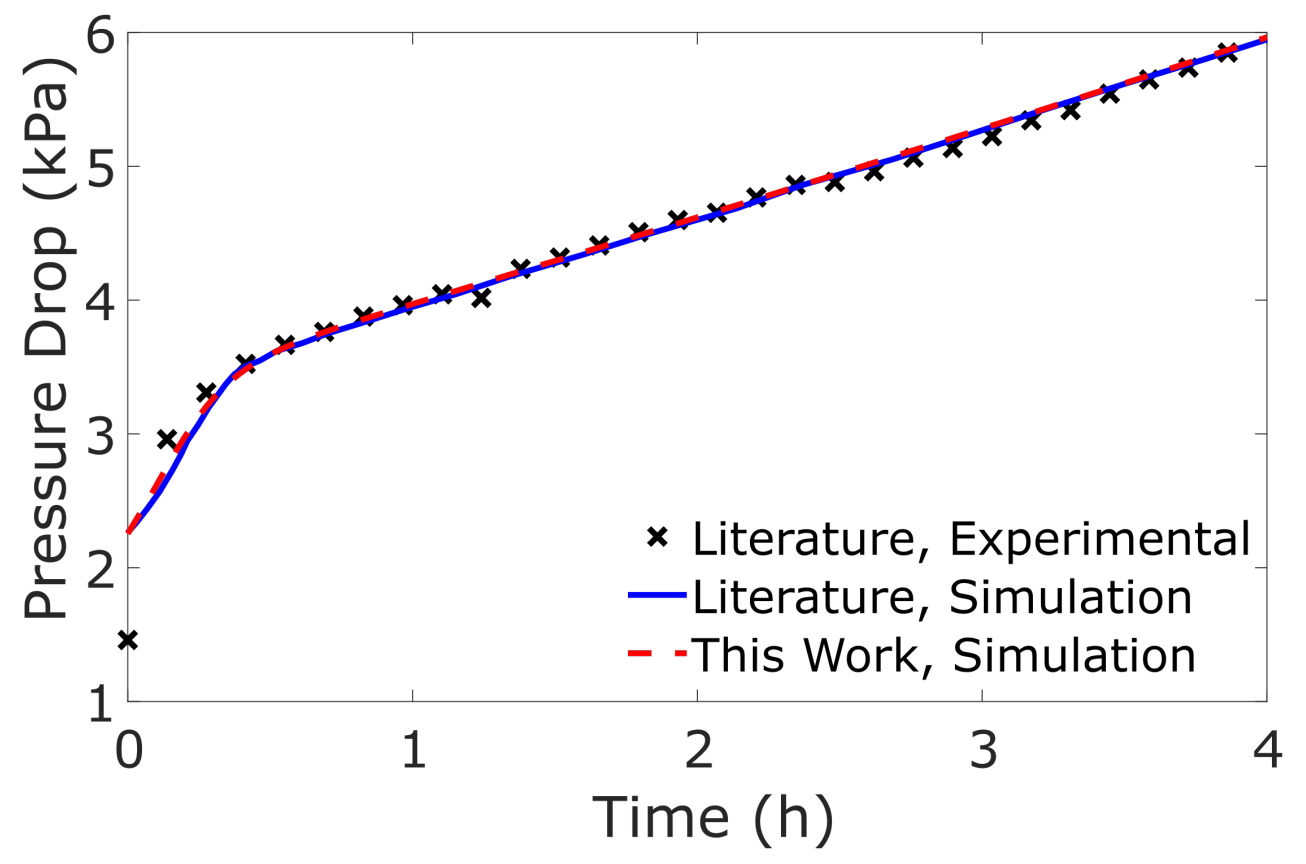

Figure 6: Comparison of model prediction of DPF backpressure by the proposed model and literature results $[73,74]$.

The ability of the proposed model to describe DPFs under active regeneration has been shown in previous work [42]. The rate parameters for active regeneration used in this work are obtained from Bissett [77]. The ability to describe passive regeneration is checked against the work of Kim et al. [78]. They simulated the variation of the mass of trapped particles inside a DPF under three inlet conditions with various NOx-to-PM ratio. The rate parameters for the passive regeneration reactions are calibrated in this work to best reproduce the results of Kim et al. [78]. The rate of passive regeneration reaction is governed by two parameters in this work: the pre-exponential 
constant and the activation energy. The value of activation energy is 95 $\mathrm{kJ} / \mathrm{mol}$ [29]. However, the literature provides no consensus for the value of the pre-exponential factor and it is treated as a calibration parameter. After calibration, the value of the pre-exponential constant is $1.5 \times 10^{25} \mathrm{~m} /(\mathrm{molKs})$. The predicted particle mass profiles after calibration are shown in Fig. 7. It can be concluded from Fig. 7 that the proposed model is capable of describing the impact of varying $\mathrm{NO}_{2}$ content on passive regeneration of DPFs.

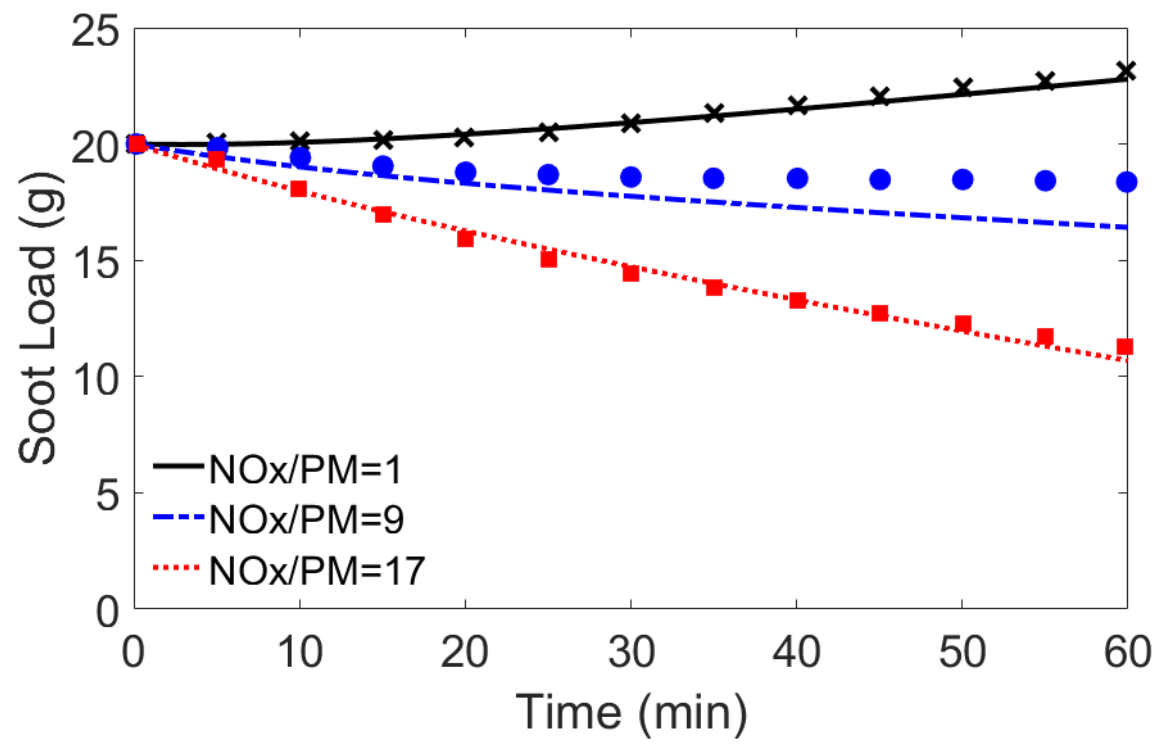

Figure 7: Comparison of model prediction of soot load during passive regeneration by the proposed model (lines) and the literature model (markers) [78].

\section{Parametric study}

In this section, the proposed EAT model is used to investigate interaction between EAT devices in DPF-front and SCR-front EAT systems. The investigation is performed in the context of the design of an EAT system for 
a heavy-duty diesel engine. First of all, simulations are performed to obtain the engine-out emissions. After that, the proposed EAT model is used to design the EAT system using both a DPF-front and SCR-front layout to meet the appropriate emission standards. The interaction between EAT devices are investigated by evaluation of the system performance and flux analysis.

\subsection{Engine simulation}

The EAT model is applied to design an EAT system for a heavy-duty diesel engine. This engine model is included in the SRM Engine Suite as "Ex.09 (6 Cylinder 7L HD Diesel LSMap TierIV)". The engine model was calibrated for 8 operating points with varying engine speed and load. The engine-out NOx concentration and the soot emissions are shown on Fig. 8. The Brake Mean Effective Pressure (BMEP) is used as a measure for engine load.
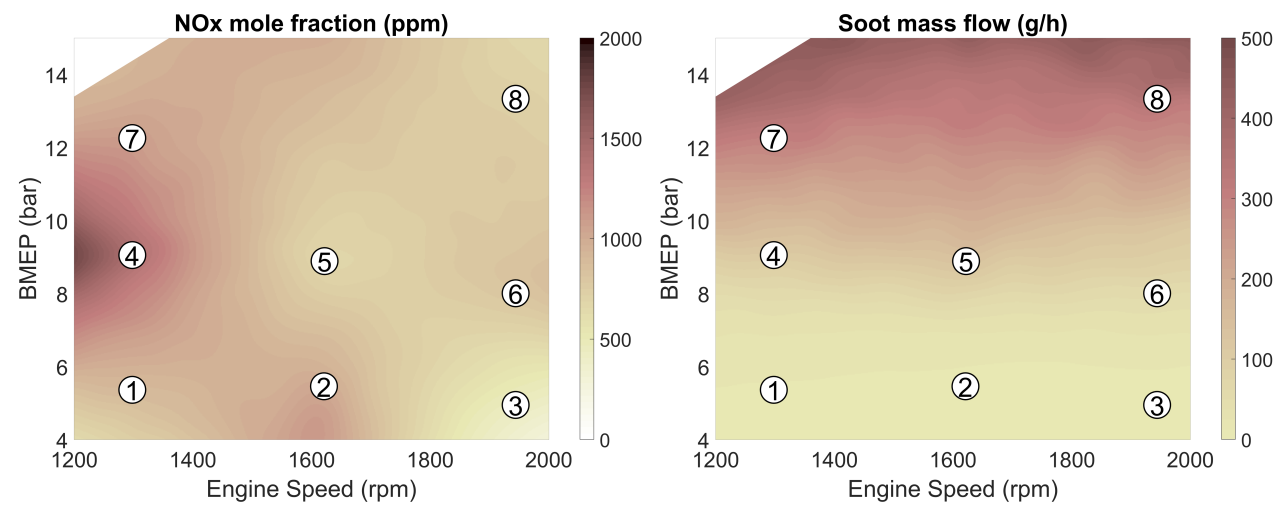

Figure 8: The predicted NOx and soot emissions of the engine used for the virtual design and testing of the exhaust after-treatment system.

The inlet conditions of the EAT system at the 8 operating points given by the SRM Engine Suite are shown in Table 2. The exhaust temperatures at 
the inlet of the after-treatment system is calculated as described in Section 2.2 .

Table 2: Inlet conditions of the EAT system studied in this work.

\begin{tabular}{llllllllll}
\hline Operating point & Unit & 1 & 2 & 3 & 4 & 5 & 6 & 7 & 8 \\
\hline Engine speed & $\mathrm{rpm}$ & 1298 & 1621 & 1944 & 1298 & 1622 & 1944 & 1298 & 1944 \\
BMEP & $\mathrm{bar}$ & 5.4 & 5.5 & 5.0 & 9.1 & 8.9 & 8.0 & 12.2 & 13.3 \\
Gas mass flow & $\mathrm{kg} / \mathrm{h}$ & 363 & 459 & 618 & 425 & 572 & 677 & 569 & 1027 \\
Gas temperature & ${ }^{\circ} \mathrm{C}$ & 275 & 286 & 251 & 389 & 388 & 355 & 433 & 437 \\
Particle mass flow & $\mathrm{kg} / \mathrm{h}$ & 0.010 & 0.007 & 0.004 & 0.116 & 0.149 & 0.059 & 0.287 & 0.454 \\
Mass fraction & & & & & & & & & \\
$\mathrm{CO}$ & $\mathrm{ppm}$ & 37 & 39 & 112 & 2080 & 4270 & 182 & 7590 & 6270 \\
$\mathrm{CO}$ & & & & & & & \\
2 & $\%$ & 19.8 & 17.1 & 21.5 & 17.6 & 22.9 & 23.3 & 17.9 & 25.9 \\
$\mathrm{H}_{2} \mathrm{O}$ & $\%$ & 4.5 & 4.2 & 4.4 & 5.6 & 6.0 & 5.6 & 6.1 & 6.7 \\
$\mathrm{O}_{2}$ & $\%$ & 11.8 & 12.4 & 12.3 & 8.9 & 8.1 & 9.1 & 7.8 & 6.6 \\
$\mathrm{~N}_{2}$ & $\%$ & 64 & 66 & 62 & 68 & 63 & 62 & 67 & 60 \\
$\mathrm{NO}$ & $\mathrm{ppm}$ & 683 & 805 & 203 & 1320 & 504 & 677 & 1030 & 629 \\
$\mathrm{NO}_{2}$ & $\mathrm{ppm}$ & 335 & 359 & 380 & 191 & 193 & 249 & 145 & 171 \\
$\mathrm{~N}_{2} \mathrm{O}$ & $\mathrm{ppm}$ & 2.5 & 2.9 & 3.7 & 2.2 & 2.9 & 3.1 & 2.4 & 3.0 \\
$\mathrm{C}_{3} \mathrm{H}_{6}$ & $\mathrm{ppm}$ & 16 & 15 & 6 & 65 & 220 & 19 & 1385 & 1010 \\
\hline
\end{tabular}

\subsection{Interaction between after-treatment devices}

In this section we examine different EAT systems designs for the 8 operating points listed in Table 2. Both DPF-front and SCR-front layouts are considered. The EAT designs are developed using emission standard IIIB and IV as objectives. The impact of the emissions standard on EAT design and performances can be extracted by comparing the systems behaviours. In 
order to examine the interaction between after-treatment devices, the lengths of individual devices are varied between designs.

Since large number of design parameters are needed to define an EAT system, thorough analysis is time consuming and may distract us from the objective of this study. Some simplifications have been applied during the design process so that the investigation can focus on the chemical phenomena. For example, the outer diameter of all catalytic EAT devices are fixed to $0.2 \mathrm{~m}$ and that of the DPF is fixed to $0.3 \mathrm{~m}$. The catalyst loadings of the SCR are chosen to be the same as Section 3. The catalyst loading of the DOC is set to $40 \mathrm{~g} / \mathrm{ft}^{3}$ to represent typical commercial DOCs [32, 46].

\subsubsection{DPF-front system}
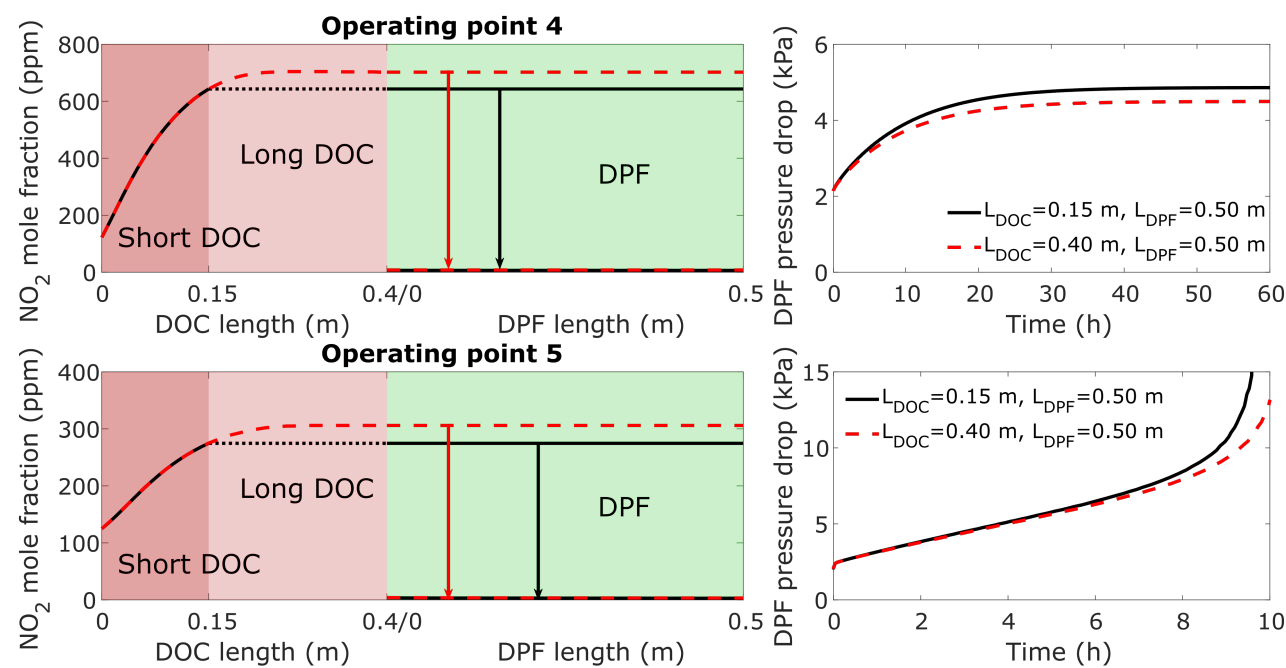

Figure 9: Impact of the length of upstream DOC on downstream DPF.

Firstly the interaction between DOC and DPF is examined. This is done by comparing the behaviours of two DOC-DPF systems where the lengths of the DOCs are $0.15 \mathrm{~m}$ and $0.4 \mathrm{~m}$ respectively. Their behaviours at operating 
point 4 and 5 are shown in Fig. 9. The concentration profiles of $\mathrm{NO}_{2}$ are shown here since it is the key reactant for passive regeneration (eq. (9)) of the DPF. It is found that active regeneration by $\mathrm{O}_{2}$ is only significant for operating point 8 , where the exhaust is hot enough to overcome the activation energy of the active regeneration reaction. $\mathrm{NO}_{2}$ is generated from $\mathrm{NO}$ by the DOC and is consumed subsequently in the DPF. It can be observed from Fig. 9 that increasing the length of the DOC leads to an increase in $\mathrm{NO}_{2}$ concentration at the inlet of the DPF. At operating point 4, there is sufficient passive regeneration to achieve steady state operation with the short DOC. Steady state operation can also be achieved at operating points $1,2,3,6$ and 7 . Increasing the length of the DOC results in a lower pressure drop across the DPF, which would have positive implications on the engine cylinder combustion efficiency. This is offset by the increased capital cost of having a longer DOC and an increase in volume of the EAT system, which can be a significant constraint.

At operating point 5, passive regeneration is insufficient to achieve steady state in the system with the short DOC. The inlet channel of the DPF is clogged by particles, resulting in rapid increase in the pressure drop after about 8 hours. Whilst increasing the length of the DOC is also unable to support sufficient regeneration within the DPF, it is capable of delaying clogging by about 1 hours. This can reduce the fuel penalty associated with active regeneration. To summarise, increasing the length of the DOC is beneficial for passive regeneration occurring in the downstream DPF regardless of whether passive regeneration is sufficient to allow continuous operation at a given operating point. 


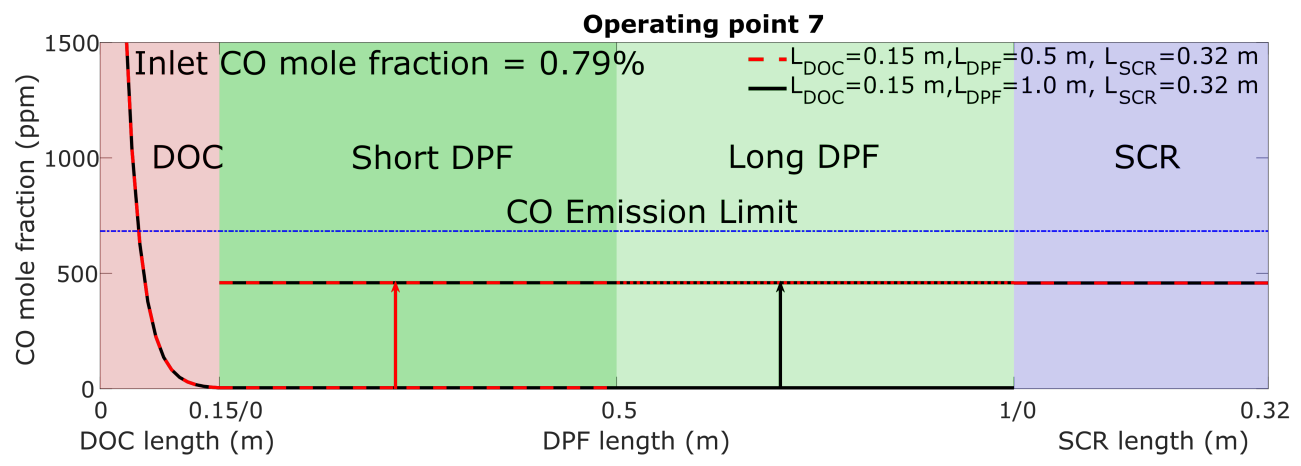

Figure 10: Secondary CO emission post-DPF due to regeneration.

Eq. (9) shows that regeneration reactions can lead to production of CO in the exhaust. The implication of this secondary CO emission is demonstrated in Fig. 10, where the CO concentration profiles along two DOC-DPF-SCR systems at operating point 7 are shown. In this case, engine-out $\mathrm{CO}$ are completely removed within the DOC. Regeneration reactions inside the DPF leads to an increase of $\mathrm{CO}$ in the exhaust. It should be noted that the length of the DPF has no impact on the steady state gas phase composition profile. This secondary $\mathrm{CO}$ emission then passes through the downstream SCR catalyst unreacted.

The interaction between $\mathrm{CO}$ and the copper zeolite catalyst was not considered during the development of the chemical mechanism in the work of Olsson et al. [44]. It is reported by Zhang et al. [79] that copper zeolite catalyst has $\mathrm{CO}$ oxidation capability. If this is also possible for the Cu-ZSM-5 catalyst, then the downstream SCR catalyst can prevent CO slip and this makes the DPF-front layout more attractive. Future investigations of SCR catalysts should also consider the possibility of $\mathrm{CO}$ oxidation in light of the secondary CO emission. 


\subsubsection{SCR-front system}

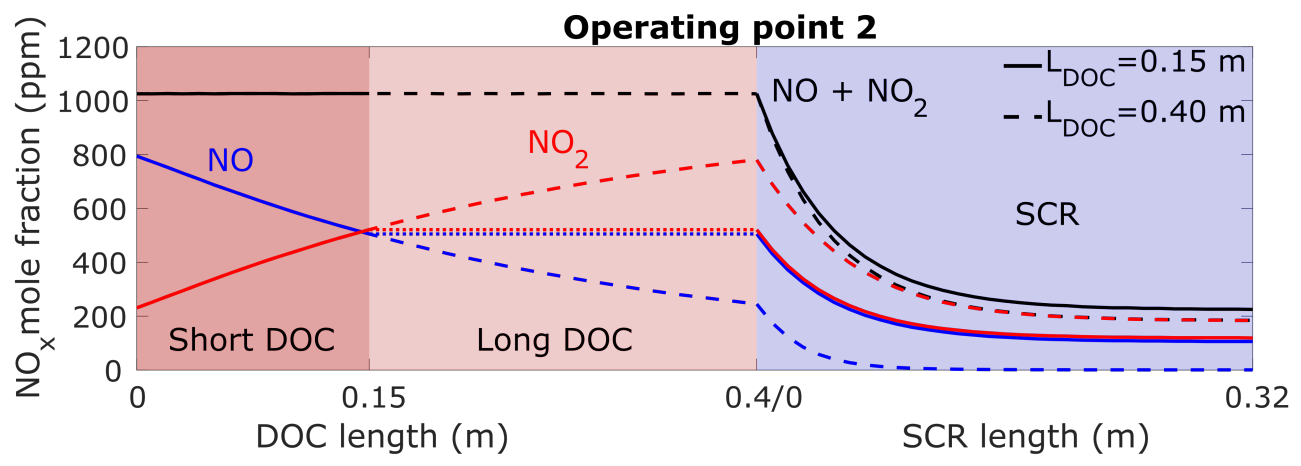

Figure 11: Impact of the length of upstream DOC on downstream SCR.

After examining the interaction between the DOC and the DPF, we investigate the interaction between the DOC and the SCR in systems with the SCR-front layout. The DOC can oxidise $\mathrm{NO}$ to $\mathrm{NO}_{2}$, which enables the "fastSCR" reaction (eq. 14) to be the dominant reaction pathway in the SCR. This claim is examined at operating point 2, where the concentration profiles of NOx are shown in Fig. 11. Two DOC-SCR systems with two different lengths of DOC are shown here. The $\mathrm{NO}_{2}$ : $\mathrm{NOx}$ ratio increased from 0.51 to 0.76 by increasing the length of the DOC from $0.15 \mathrm{~m}$ to $0.4 \mathrm{~m}$. It should be noted that the total amount of NOx in the exhaust remains unchanged through the DOC.

There is little benefit of having a longer DOC. The overall deNOx efficiency is slightly improved by having a longer DOC at the expense of $11 \%$ increase in $\mathrm{NH}_{3}$ dosing. In order to further investigate the influence of the upstream DOC on the performance of the SCR, flux analysis is applied and the results are discussed in section 4.2.3.

Fig. 11 has shown that whilst having a longer DOC has little impact on the 

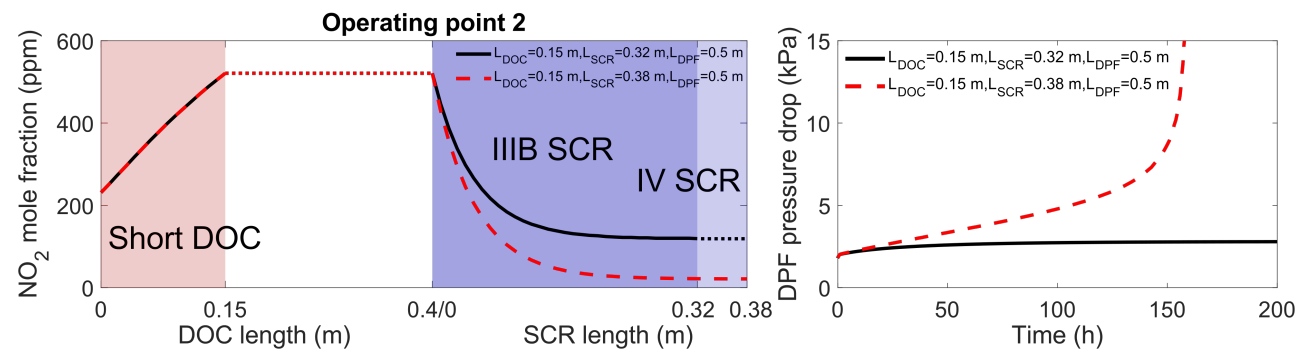

(a) Respective performances of SCR-front systems designed to meet Stage IIIB and Stage IV standard.
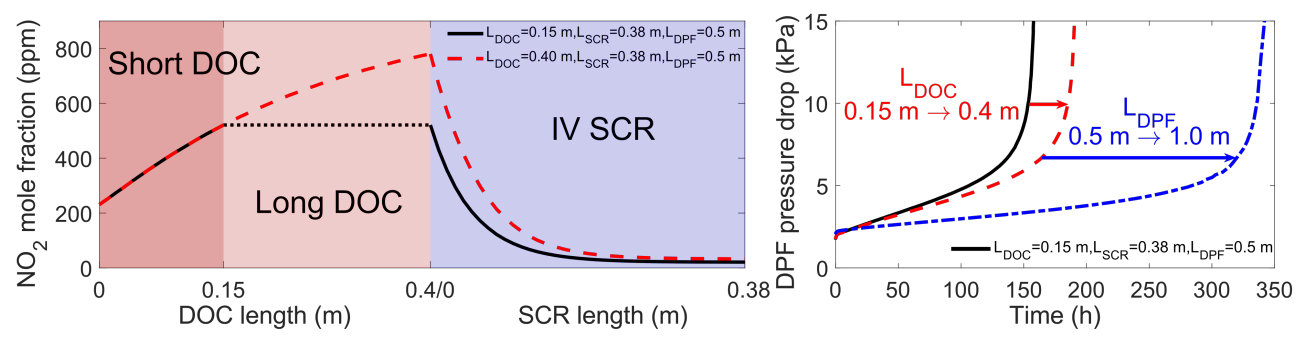

(b) Evaluation of the possibility of sufficient passive regeneration with Stage IVcompliant SCR-front systems.

Figure 12: Examination of the possibility to have sufficient passive regeneration for steady state operation with SCR-front system.

overall deNOx efficiency, it increased the amount of $\mathrm{NO}_{2}$ at the outlet of the SCR, which is the inlet of the DPF in a SCR-front system. This leads to more $\mathrm{NO}_{2}$ at the exit of the SCR catalyst, which can aid passive regeneration in a downstream DPF. Here we examine the possibility of steady state operation for EAT systems with SCR-front layout. For a Stage IIIB compliant design, it is found that there is sufficient passive regeneration occurring in the DPF to achieve steady state at operating point 2, as shown in Fig. 12(a). In addition, this design is able to achieve steady state at operating point 3 and 7. 
In order to comply with the Stage IV standard where the NOx limit decreased from $2.0 \mathrm{~g} / \mathrm{kWh}$ to $0.4 \mathrm{~g} / \mathrm{kWh}$ [80], the length of the SCR and the amount of $\mathrm{NH}_{3}$ injection must increase. When the length of the SCR is increased from $0.32 \mathrm{~m}$ to $0.38 \mathrm{~m}$, steady state operation is only achievable at operating point 7 . At operating point 2 , the inlet $\mathrm{NO}_{2}$ concentration for the DPF has dropped from $120 \mathrm{ppm}$ to $20 \mathrm{ppm}$, which leads to decreased regeneration activity in the DPF and ultimately DPF clogging.

Alternative designs are explored to see whether steady state operation in the DPF is possible for a Stage IV compliant SCR-front EAT system. The behaviours of those systems are shown in Fig. 12(b). Firstly the length of the DOC is increased. However, the impact of the DOC is nullified by the SCR catalyst; the inlet $\mathrm{NO}_{2}$ concentration for the DPF has only increased from $20 \mathrm{ppm}$ to $30 \mathrm{ppm}$ despite significant increase in DOC size. Fig. 12 shows that steady state operation is not possible, even with a larger DPF, since the size of the DPF does not affect the steady state gas phase composition profile. Similar to previous findings, increasing the length of the DPF can delay clogging but does not mitigate the need for active regeneration.

\subsubsection{Flux Analysis}

Flux analysis is a technique to investigate reaction mechanisms [81]. It allows better understanding of the behaviour of a system by tracking how elements are "transferred" between chemical species via various reaction pathways. With flux analysis, we can identify the relative importance of the different reaction pathways.

In this case flux analysis is applied to the SCR catalyst with different upstream DOCs at operating point 2. The behaviour of the system is shown 
in Fig. 11. The fluxes of nitrogen atoms are analysed since SCR is designed to reduce NOx to $\mathrm{N}_{2}$. Details of the calculations of reaction fluxes can be found in work of Nurkowski et al. [81]. The fluxes of nitrogen atoms inside the SCR at operating point 2 with upstream DOCs of lengths $0.15 \mathrm{~m}$ and $0.4 \mathrm{~m}$ is shown in Fig. 13.

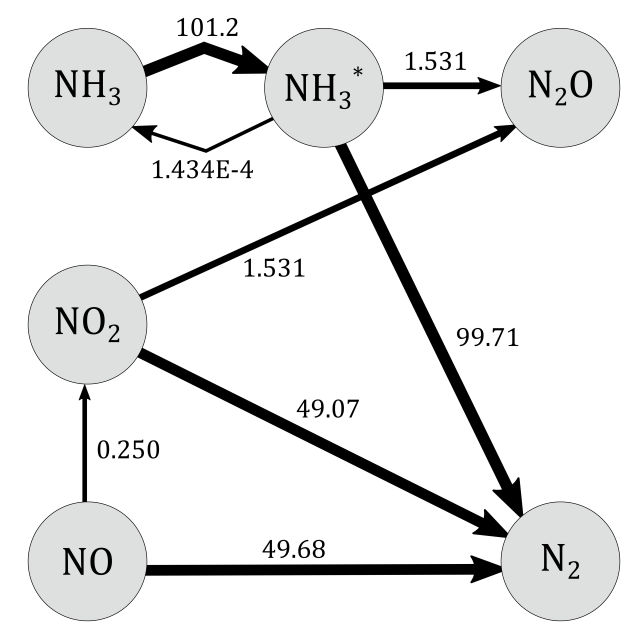

(a) Flux with DOC length $0.15 \mathrm{~m}$.

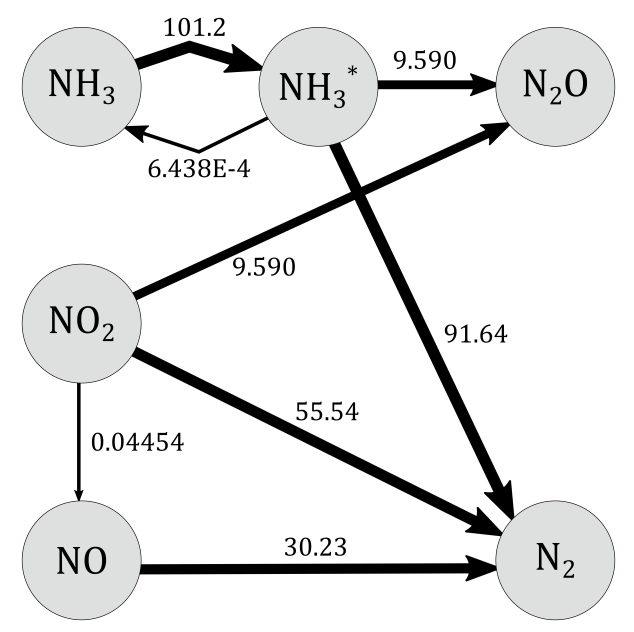

(b) Flux with DOC length $0.4 \mathrm{~m}$.

Figure 13: Flux of Nitrogen in the SCR with upstream DOCs of lengths $0.15 \mathrm{~m}$ and $0.4 \mathrm{~m}$ at operating point 2 . The fluxes of nitrogen atoms $\left(\mathrm{mol} / \mathrm{m}^{3} \mathrm{~s}\right)$ are integrated along the entire length of the SCR.

We can observe that nitrogen atoms "flow" from $\mathrm{NOx}$ and $\mathrm{NH}_{3}$ to $\mathrm{N}_{2}$ as well as a undesirable by-product $\mathrm{N}_{2} \mathrm{O}$. The net fluxes of nitrogen from adsorbed $\mathrm{NH}_{3}$ (shown as $\mathrm{NH}_{3}{ }^{*}$ in Fig. 13), $\mathrm{NO}$ and $\mathrm{NO}_{2}$ to $\mathrm{N}_{2}$ are due to SCR reactions taking place. In addition, the Cu-ZSM-5 catalyst also exhibits $\mathrm{NO}$ oxidation activity as reflected by the nitrogen flux from $\mathrm{NO}$ to $\mathrm{NO}_{2}$.

We can clearly see the impact of varying the length of the upstream DOC on the SCR by comparing Fig. 13(a) and 13(b). The fluxes from 
adsorbed $\mathrm{NH}_{3}$ to $\mathrm{N}_{2}$ for both systems are similar, indicating similar overall deNOx performances. However, the system with the longer DOC would lead to increased amount of $\mathrm{NO}_{2}$ at the inlet of the SCR, and this leads to corresponding increase in fluxes from $\mathrm{NO}_{2}$ to $\mathrm{N}_{2}$ and $\mathrm{N}_{2} \mathrm{O}$. The direction of the net flux between $\mathrm{NO}$ and $\mathrm{NO}_{2}$ is since the extent of $\mathrm{NO}$ oxidation is limited by equilibrium.

Further analysis was performed to study the system behaviour with a wider range of $\mathrm{NO}_{2} / \mathrm{NOx}$ ratio. The minimum $\mathrm{NO}_{2} / \mathrm{NOx}$ ratio (0.23) can be achieved if the SCR is the first device in the EAT system. The nitrogen fluxes are shown as stacked bars on Fig. 14. The contributions of standard $\mathrm{SCR}$, fast $\mathrm{SCR}$ and $\mathrm{NO}_{2} \mathrm{SCR}$ as well as the $\mathrm{N}_{2} \mathrm{O}$ producing side-reaction vary with the inlet $\mathrm{NO}_{2} / \mathrm{NOx}$ ratio.

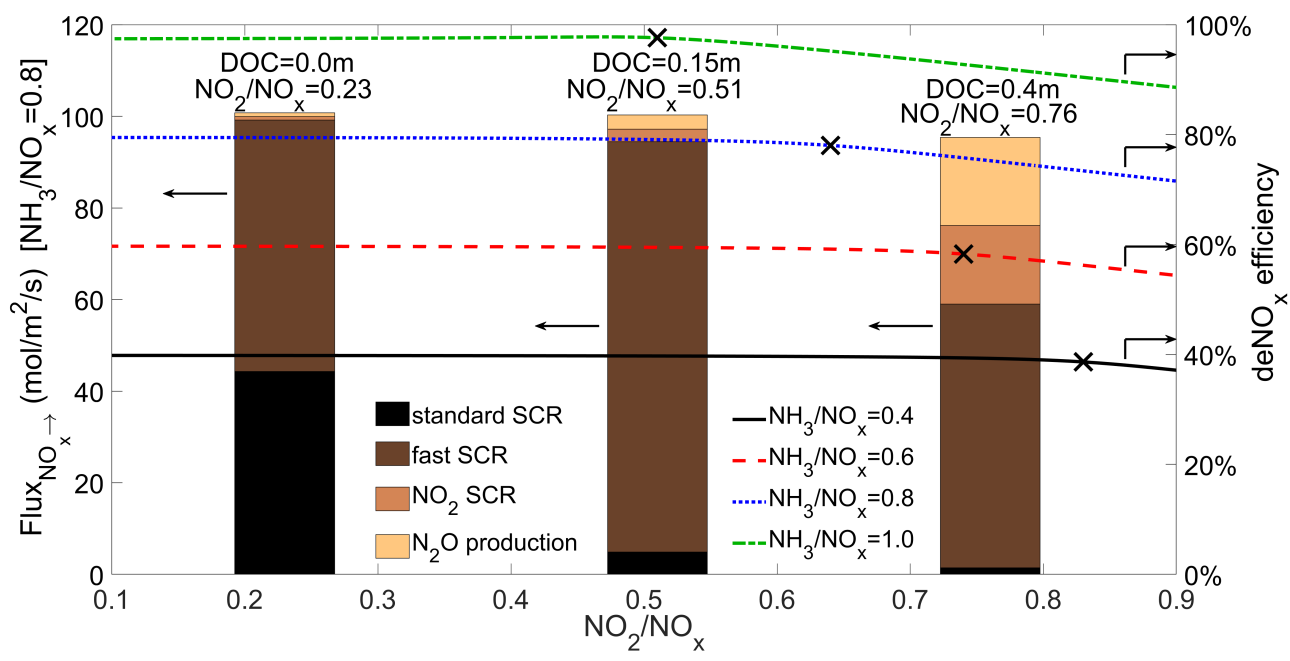

Figure 14: The variation in deNOx efficiency of the SCR with different inlet $\mathrm{NO}_{2} / \mathrm{NOx}$. The fluxes of nitrogen atoms from NOx to other species are shown as stacked bars for three DOC-SCR systems. The nitrogen flux correlates to the efficiency of the SCR. The critical $\mathrm{NO}_{2} / \mathrm{NOx}$ ratio for each $\mathrm{NH}_{3}$ dosing are shown as crosses. 
In addition to the nitrogen fluxes shown on the left vertical axis, the deNOx efficiencies under different inlet $\mathrm{NOx}$ ratio at four $\mathrm{NH}_{3}$ dosage levels are shown as curves on the right vertical axis. The deNOx efficiencies are at their respective minimum when the inlet contains $100 \% \mathrm{NO}_{2}$. By reducing the amount of $\mathrm{NO}_{2}$ at the inlet, the $\mathrm{SCR}$ becomes more efficient at fixed $\mathrm{NH}_{3}$ dosage. The critical $\mathrm{NO}_{2} / \mathrm{NOx}$ ratio for deNOx efficiency is marked on the four efficiency curves.

It is observed that the total nitrogen flux from NOx correlates with the deNOx efficiency. The decrease in efficiency at high $\mathrm{NO}_{2}$ content can be explained by the individual flux contributions. The contributions of the fast SCR and the standard SCR to NOx removal are lowest when the $\mathrm{NO}_{2} / \mathrm{NOx}$ $=0.76$ at the SCR inlet. Furthermore, the flux of $\mathrm{N}_{2} \mathrm{O}$ production is the highest, which is undesirable since $\mathrm{N}_{2} \mathrm{O}$ is a strong greenhouse gas [72].

The results of flux analysis can shed light on decisions needed when designing EAT systems. In this case, increasing the length of the DOC to $0.4 \mathrm{~m}$ has little benefit on the downstream SCR since the increased activity of fast SCR reaction is counter-balanced by the decrease in standard SCR activity. Whilst these conclusions are limited to this particular catalyst, flux analysis have been shown to be useful for other EAT design problems.

\subsubsection{Comparison between DPF-front and SCR-front layout}

It is apparent that the DPF-front system is superior with respect to the SCR-front system in terms of regeneration strategy. The DPF-front system is able to achieve steady state with sufficient passive regeneration activities for 6 out of 8 operating points investigated. On the other hand the Stage IIIB compliant SCR-front system can only reach steady state at 3 oper- 
ating points. Passive regeneration activities can reduce the fuel penalties associated with active regeneration. When emission standards become more stringent, passive regeneration in the SCR-front system is further limited as shown in Fig. 12. This implies an increase in the need for active regeneration. Furthermore, the CO generated from DPF regeneration may be treated by the downstream SCR catalyst in a DPF-front system, since the copper zeolite catalyst may be able to oxidise CO. This remains to be investigated.

Whilst more $\mathrm{NO}_{2}$ is available to the SCR in SCR-front systems, the overall deNOx efficiency is not improved. Flux analysis in Section 4.2.3 has shown that the benefit of increased fast SCR activity due to higher $\mathrm{NO}_{2}$ content is cancelled by a decrease in standard SCR activity.

In conclusion, the DPF-front layout has been shown to have better steady state performance compared to the SCR-front layout in this case study. The benefit of higher passive regeneration activities is clearly shown, whereas an increase of the fast SCR activity has no significant impact on the overall deNOx performance of the EAT system under steady state operation.

\section{Conclusions}

A single channel EAT model with rigorous treatment for the catalytic chemistry has been proposed in this study. The performances of the proposed model for simulating a DOC, SCR and DPF are compared with experimental and simulation data from the literature. The proposed model has been shown to be able to describe the behaviours of relevant after-treatment devices with sufficient accuracy given the simplified treatment for mass transfer phenomena. The proposed model is then applied to design after-treatment 
systems for a heavy duty diesel engine simulated using virtual engine software. The steady state behaviours of designs with different configurations, emission standards requirements and lengths of individual devices are investigated.

The DOC is found to promote passive regeneration in a downstream DPF which may be able to be exploited to reduce the fuel penalty associated with active regeneration frequency and backpressure. However, it is not always possible to achieve steady state operation of the passive regeneration by increasing the size of the DOC. Furthermore, increased regeneration activity could lead to significant secondary CO emissions post-DPF which cannot be treated by the DOC. In the DPF-front configuration, the CO generated during passive regeneration was found to pass through the modelled SCR without reacting. The SCR mechanism adopted in this study does not consider interaction between $\mathrm{CO}$ and the SCR catalyst. This should be considered in future studies on SCR chemistry. This study has not found the reportedly positive impact of an upstream DOC on the SCR catalyst [30]. Further flux analysis suggests that the particular SCR catalyst studied is insensitive to the $\mathrm{NO}_{2}$ portion at its inlet, for the range of possible inlet species concentrations provided by the DOCs considered in this design study.

It was found that as more stringent emission standards are adopted, the possibility of passive regeneration is reduced for SCR-front EAT systems. The NOx emission limits constrains the sizing of the SCR catalyst, which is the only device with net NOx conversion along after-treatment devices included in this study. In addition, it is possible that the SCR catalyst exhibits $\mathrm{CO}$ oxidation activity and therefore the SCR catalyst can help to 
mitigate secondary $\mathrm{CO}$ emissions due to DPF regeneration in a DPF-front system. To summarise, the DPF-front design is superior to the SCR-front design for this case study, and it is expected to become more popular in the future.

This study has focused on the steady state performance and chemical interaction of the EAT systems. Future studies on chemical interaction of multi-device EAT systems should be extended to consider transient and thermal behaviour of EAT systems under more complicated operating conditions including cold-start behaviour and active regeneration. The numerical model should be further developed to be able to simulate more advanced, integrated EAT devices such as catalysed particulate filters and dual-layer catalysts.

\section{Supplementary material}

Additional data related to this publication is available at the University of Cambridge data repository (https://doi .org/10.17863/CAM .40283).

\section{Acknowledgements}

The authors would like to thank Cambridge Centre for Advanced Research and Education in Singapore (CARES), Engineering and Physical Sciences Research Council (EPSRC) and Royal Dutch Shell for their support. This project has received funding from the European Union's Horizon 2020 Research and Innovation Programme under grant agreement no. 724145.

\section{Nomenclature}




\begin{tabular}{|c|c|c|}
\hline $\begin{array}{l}\text { Roman } \\
\text { symbols }\end{array}$ & Meaning & Unit \\
\hline$A$ & Pre-exponential constant & $(\mathrm{mol}, \mathrm{cm}, \mathrm{s})$ \\
\hline$B$ & Temperature exponent & - \\
\hline$c$ & Molar concentration of gas species & $\mathrm{mol} / \mathrm{m}^{3}$ \\
\hline$D$ & $\begin{array}{l}\text { Side length of square channel cross- } \\
\text { section }\end{array}$ & $\mathrm{m}$ \\
\hline$D_{\mathrm{m}}$ & Molar diffusivity & $\mathrm{m}^{2} / \mathrm{s}$ \\
\hline$d_{\mathrm{p}}$ & Diameter of particle & $\mathrm{m}$ \\
\hline E & Activation energy & $\mathrm{kJ} / \mathrm{mol}$ \\
\hline$F$ & Friction factor & - \\
\hline$J$ & Total number of connections & - \\
\hline$k$ & Reaction rate constant & $(\mathrm{mol}, \mathrm{cm}, \mathrm{s})$ \\
\hline$L$ & $\begin{array}{l}\text { Length between centres of adjacent } \\
\text { volume elements }\end{array}$ & $\mathrm{m}$ \\
\hline$M$ & Molar mass & $\mathrm{kg} / \mathrm{mol}$ \\
\hline$\dot{m}$ & Gas mass flow rate & $\mathrm{kg} / \mathrm{s}$ \\
\hline$N$ & Particle number density & $1 / \mathrm{m}^{3}$ \\
\hline$\dot{N}$ & Flow rate of particle number density & $1 / \mathrm{m}^{3} \mathrm{~s}$ \\
\hline$n$ & Number of mole & mol \\
\hline$P$ & Pressure & $\mathrm{Pa}$ \\
\hline$Q$ & Filtration efficiency & - \\
\hline
\end{tabular}




\begin{tabular}{|c|c|c|}
\hline $\begin{array}{l}\text { Roman } \\
\text { symbols }\end{array}$ & Meaning & Unit \\
\hline$R$ & Universal gas constant & $\mathrm{kJ} / \mathrm{molK}$ \\
\hline$r$ & Rate of reaction & $\mathrm{mol} / \mathrm{m}^{3} \mathrm{~s}$ \\
\hline$S$ & Reactive surface area & $\mathrm{m}^{2}$ \\
\hline$S h$ & Sherwood number & - \\
\hline$T$ & Temperature & $\mathrm{K}$ \\
\hline$t$ & Time & $\mathrm{s}$ \\
\hline$u$ & Channel gas flow velocity & $\mathrm{m} / \mathrm{s}$ \\
\hline$V$ & Volume & $\mathrm{m}^{3}$ \\
\hline$W$ & Total number of reactions & - \\
\hline$v$ & Through-wall gas flow velocity & $\mathrm{m} / \mathrm{s}$ \\
\hline$X$ & Reaction order & - \\
\hline$x$ & Mole fraction & - \\
\hline$Y$ & Mass fraction of gas species & - \\
\hline $\begin{array}{l}\text { Greek sym- } \\
\text { bols }\end{array}$ & Meaning & Unit \\
\hline$\alpha$ & $\begin{array}{l}\text { Stoichiometric constant for regener- } \\
\text { ation }\end{array}$ & - \\
\hline$\Gamma$ & Total number of gas phase species & - \\
\hline$\zeta$ & Surface concentration & $\mathrm{mol} / \mathrm{m}^{2}$ \\
\hline
\end{tabular}




\begin{tabular}{|c|c|c|}
\hline $\begin{array}{l}\text { Greek sym- } \\
\text { bols }\end{array}$ & Meaning & Unit \\
\hline$\eta$ & Effectiveness factor & - \\
\hline$\theta$ & Site fraction & - \\
\hline$\kappa$ & Permeability & $\mathrm{m}^{2}$ \\
\hline$\mu$ & Gas viscosity & Pa.s \\
\hline$\nu$ & Stoichiometric coefficient & - \\
\hline$\rho$ & Dynamic density & $\mathrm{kg} / \mathrm{m}^{3}$ \\
\hline$\rho_{\mathrm{m}}$ & Molar density & $\mathrm{mol} / \mathrm{m}^{3}$ \\
\hline$\sigma$ & Coverage dependent parameter & - \\
\hline$\Psi$ & Total number of surface species & - \\
\hline Subscript & Meaning & \\
\hline$i$ & Volume element index & \\
\hline$w$ & Reaction index & \\
\hline$\gamma$ & Gas species index & \\
\hline$\beta$ & Surface species index & \\
\hline$z$ & Particle size class index & \\
\hline in & Inlet & \\
\hline out & Outlet & \\
\hline $\operatorname{ch}$ & channel & \\
\hline AR & Active regeneration & \\
\hline
\end{tabular}




\begin{tabular}{ll}
\hline Subscript & Meaning \\
\hline PR & Passive regeneration \\
\hline
\end{tabular}

[1] G. T. Kalghatgi, Developments in internal combustion engines and implications for combustion science and future transport fuels, Proceedings of the Combustion Institute 35 (2015) 101-115. doi:10.1016/j.proci. 2014.10.002.

[2] https://www.acea.be/uploads/statistic_documents/Economic_ and_Market_Report_Q2_2018.pdf, 2018.

[3] https://www .acea.be/uploads/statistic_documents/ACEA_ Report_Vehicles_in_use-Europe_2018.pdf, 2018.

[4] C. L. Townsend, R. L. Maynard, Effects on health of prolonged exposure to low concentrations of carbon monoxide, Occupational and Environmental Medicine 59 (2002) 708-711. doi:10.1136/oem.59.10.708.

[5] L. Caprino, G. I. Togna, Potential health effects of gasoline and its constituents: A review of current literature (1990-1997) on toxicological data, Environmental Health Perspectives 106 (1998) 115-125. doi:10. 1289/ehp. 98106115.

[6] G. Triantafyllopoulos, D. Katsaounis, D. Karamitros, L. Ntziachristos, Z. Samaras, Experimental assessment of the potential to decrease diesel NOx emissions beyond minimum requirements for Euro 6 Real Drive Emissions (RDE) compliance, Science of the Total Environment 618 (2017) 1400-1407. doi:10.1016/j .scitotenv . 2017.09. 274. 
[7] J. Lelieveld, J. S. Evans, M. Fnais, D. Giannadaki, A. Pozzer, The contribution of outdoor air pollution sources to premature mortality on a global scale, Nature 525 (2015) 367-371. doi:10.1038/nature15371. arXiv:arXiv:1011.1669v3.

[8] K. H. Kim, E. Kabir, S. Kabir, A review on the human health impact of airborne particulate matter, Environment International 74 (2015) 136-143. doi:10.1016/j.envint.2014.10.005.

[9] V. Ramanathan, G. Carmichael, V. Ramanathan and G. Carmichael, V. Ramanathan, G. Carmichael, Global and regional climate changes due to black carbon, Nature Geoscience 1 (2008) 221 - 227. doi:10. 1038/ngeo156.

[10] S. H. Kamble, T. V. Mathew, G. Sharma, Development of real-world driving cycle: Case study of Pune, India, Transportation Research Part D: Transport and Environment 14 (2009) 132-140. doi:10.1016/j.trd. 2008.11.008.

[11] M. Tutuianu, P. Bonnel, B. Ciuffo, T. Haniu, N. Ichikawa, A. Marotta, J. Pavlovic, H. Steven, Development of the World-wide harmonized Light duty Test Cycle (WLTC) and a possible pathway for its introduction in the European legislation, Transportation Research Part D: Transport and Environment 40 (2015) 61-75. doi:10.1016/j.trd. 2015. 07.011.

[12] S. K. Hoekman, C. Robbins, Review of the effects of biodiesel on NOx 
emissions, Fuel Processing Technology 96 (2012) 237-249. doi:10.1016/ j.fuproc.2011.12.036.

[13] Y. Ma, M. Zhu, D. Zhang, Effect of a homogeneous combustion catalyst on the characteristics of diesel soot emitted from a compression ignition engine, Applied Energy 113 (2014) 751-757. doi:10.1016/j.apenergy. 2013.08 .028 .

[14] B. Guan, R. Zhan, H. Lin, Z. Huang, Review of state of the art technologies of selective catalytic reduction of NOx from diesel engine exhaust, Applied Thermal Engineering 66 (2014) 395-414. doi:10.1016/ j.applthermaleng.2014.02.021.

[15] M. Ahmadinejad, M. R. Desai, T. C. Watling, A. P. York, Simulation of automotive emission control systems, Automotive Emission Control 33 (2007) 47-101. doi:10.1016/S0065-2377(07)33002-0.

[16] W. S. Epling, L. E. Campbell, A. Yezerets, N. W. Currier, J. E. Parks, Overview of the fundamental reactions and degradation mechanisms of NOx storage/reduction catalysts, Catal. Rev. Sci. Eng. 46 (2004) 163245. doi:10.1081/cr-200031932.

[17] S. Roy, A. Baiker, NOx Storage - Reduction Catalysis : From Mechanism and Materials Properties to Storage - Reduction Performance, Chemical Reviews 109 (2009) 4054-4091. doi:10.1021/cr800496f.

[18] P. Forzatti, L. Lietti, I. Nova, E. Tronconi, Diesel NOx aftertreatment catalytic technologies: Analogies in LNT and SCR catalytic chemistry, 
Catalysis Today 151 (2010) 202-211. doi:10.1016/j.cattod.2010.02. 025.

[19] İ. A. Reşitoğlu, K. Altinişik, A. Keskin, The pollutant emissions from diesel-engine vehicles and exhaust aftertreatment systems, Clean Technologies and Environmental Policy 17 (2014) 15-27. doi:10.1007/ s10098-014-0793-9.

[20] M. K. Kim, P. S. Kim, H. J. Kwon, I. S. Nam, B. K. Cho, S. H. Oh, Simulation of $\mathrm{OHC} / \mathrm{SCR}$ process over $\mathrm{Ag} / \mathrm{Al}_{2} \mathrm{O}_{3}$ catalyst for removing NOx from diesel engine, Chemical Engineering Journal 209 (2012) 280292. doi:10.1016/j.cej.2012.08.002.

[21] V. D. Dasireddy, B. Likozar, Selective catalytic reduction of NOx by $\mathrm{CO}$ over bimetallic transition metals supported by multi-walled carbon nanotubes (MWCNT), Chemical Engineering Journal 326 (2017) 886900. doi:10.1016/j.cej .2017.06 .019.

[22] J. Ko, W. Si, D. Jin, C.-L. Myung, S. Park, Effect of active regeneration on time-resolved characteristics of gaseous emissions and size-resolved particle emissions from light-duty diesel engine, Journal of Aerosol Science 91 (2016) 62-77. doi:10.1016/j.jaerosci.2015.09.007.

[23] B. Zhang, J. E, J. Gong, W. Yuan, W. Zuo, Y. Li, J. Fu, Multidisciplinary design optimization of the diesel particulate filter in the composite regeneration process, Applied Energy 181 (2016) 14-28. doi:10.1016/j . apenergy . 2016.08.051. 
[24] S. Bensaid, C. J. Caroca, N. Russo, D. Fino, Detailed investigation of non-catalytic DPF regeneration, Canadian Journal of Chemical Engineering 89 (2011) 401-407. doi:10.1002/cjce. 20408.

[25] K. Yamamoto, Y. Kanamori, Measurements of size distribution and oxidation rate of pm with $\mathrm{NO}_{2}$, SAE Technical Paper (2015). doi:10. 4271/2015-01-1995.

[26] R. Ramdas, E. Nowicka, R. Jenkins, D. Sellick, C. Davies, S. Golunski, Using real particulate matter to evaluate combustion catalysts for direct regeneration of diesel soot filters, Applied Catalysis B: Environmental 176 (2015) 436-443. doi:10.1016/j .apcatb. 2015.04.031.

[27] J. Zhang, V. W. Wong, S. Shuai, Y. Chen, A. Sappok, Quantitative estimation of the impact of ash accumulation on diesel particulate filter related fuel penalty for a typical modern on-road heavy-duty diesel engine, Applied Energy 229 (2018) 1010-1023. doi:10.1016/j . apenergy . 2018.08 .071$.

[28] T. Kirchner, G. Eigenberger, Optimization of the cold-start behaviour of automotive catalysts using an electrically heated pre-catalyst, Chemical Engineering Science 51 (1996) 2409-2418. doi:10.1016/0009-2509(96) 00097-8.

[29] I. P. Kandylas, G. C. Koltsakis, $\mathrm{NO}_{2}$-assisted regeneration of diesel particulate filters: A modeling study, Industrial \& Engineering Chemistry Research 41 (2002) 2115-2123. doi:10.1021/ie010842m. 
[30] C. Ciardelli, I. Nova, E. Tronconi, D. Chatterjee, B. Bandl-Konrad, M. Weibel, B. Krutzsch, Reactivity of $\mathrm{NO} / \mathrm{NO}_{2}-\mathrm{NH}_{3} \mathrm{SCR}$ system for diesel exhaust aftertreatment: Identification of the reaction network as a function of temperature and $\mathrm{NO}_{2}$ feed content, Applied Catalysis B: Environmental 70 (2007) 80-90. doi:10.1016/j . apcatb.2005.10.041.

[31] D. Rothe, M. Knauer, G. Emmerling, D. Deyerling, R. Niessner, Emissions during active regeneration of a diesel particulate filter on a heavy duty diesel engine: Stationary tests, Journal of Aerosol Science 90 (2015) 14-25. doi:10.1016/j.jaerosci.2015.07.007.

[32] A. Gurupatham, Y. He, Architecture Design and Analysis of Diesel Engine Exhaust Aftertreatment System and Comparative Study with Close-coupled DOC-DPF System, SAE Int. J. Fuels Lubr. 1 (2008) 1387-1396. doi:10.4271/2008-01-1756.

[33] B. Guan, R. Zhan, H. Lin, Z. Huang, Review of the state-of-theart of exhaust particulate filter technology in internal combustion engines, Journal of Environmental Management 154 (2015) 225-258. doi:10.1016/j j jenvman.2015.02.027.

[34] P. Chen, J. Wang, Air-fraction modeling for simultaneous Diesel engine NOx and PM emissions control during active DPF regenerations, Applied Energy 122 (2014) 310-320. doi:10.1016/j.apenergy.2014.02. 031.

[35] L. Wei, F. Yan, J. Hu, G. Xi, B. Liu, J. Zeng, NOx conversion efficiency optimization based on NSGA-II and state-feedback nonlinear 
model predictive control of selective catalytic reduction system in diesel engine, Applied Energy 206 (2017) 959-971. doi:10.1016/j . apenergy . 2017.08 .223$.

[36] J. Chen, H. Yang, N. Wang, Z. Ring, T. Dabros, Mathematical modeling of monolith catalysts and reactors for gas phase reactions, Applied Catalysis A: General 345 (2008) 1-11. doi:10.1016/j . apcata. 2008. 04. 010.

[37] C. Depcik, D. Assanis, One-dimensional automotive catalyst modeling, Progress in Energy and Combustion Science 31 (2005) 308-369. doi:10. $1016 / j \cdot$ pecs. 2005.08 .001$.

[38] S. E. Voltz, C. R. Morgan, D. Liederman, S. M. Jacob, Kinetic Study of Carbon Monoxide and Propylene Oxidation on Platinum Catalysts, Industrial \& Engineering Chemistry Product Research and Development 12 (1973) 294-301. doi:10.1021/i360048a006.

[39] A. S. Kota, D. Luss, V. Balakotaiah, Micro-kinetics of NOx storage and reduction with $\mathrm{H}_{2} / \mathrm{CO} / \mathrm{C}_{3} \mathrm{H}_{6}$ on $\mathrm{Pt} / \mathrm{BaO} / \mathrm{Al}_{2} \mathrm{O}_{3}$ monolith catalysts, Chemical Engineering Journal 262 (2015) 541-551. doi:10.1016/j.cej . 2014.09 .060 .

[40] L. Mukadi, R. Hayes, Modelling the three-way catalytic converter with mechanistic kinetics using the Newton-Krylov method on a parallel computer, Computers \& Chemical Engineering 26 (2002) 439-455. doi:10.1016/S0098-1354(01)00763-3. 
[41] Regulation (EU) 2016/1628 of the European Parliament and of the Council on requirements relating to gaseous and particulate pollutant emission limits and type-approval for internal combustion engines for non-road mobile machinery, amending Regulations (EU) No 1024/2012 and (EU) No 167/2013, and amending and repealing Directive $97 / 68 / \mathrm{EC}, 2016$.

[42] C. T. Lao, J. Akroyd, N. Eaves, A. Smith, N. Morgan, A. Bhave, M. Kraft, Modelling particle mass and particle number emissions during the active regeneration of diesel particulate filters, Proceedings of the Combustion Institute 37 (2019) 4831-4838. doi:10.1016/j.proci. 2018.07.079.

[43] M. Schejbal, M. Marek, M. Kubíček, P. Kočí, Modelling of diesel filters for particulates removal, Chemical Engineering Journal 154 (2009) 219230. doi:10.1016/j.cej.2009.04.056.

[44] L. Olsson, H. Sjövall, R. J. Blint, A kinetic model for ammonia selective catalytic reduction over Cu-ZSM-5, Applied Catalysis B: Environmental 81 (2008) 203-217. doi:10.1016/j. apcatb.2007.12.011.

[45] G. P. Smith, D. M. Golden, M. Frenklach, N. W. Moriarty, B. Eiteneer, M. Goldenberg, C. T. Bowman, R. K. Hanson, S. Song, W. C. Gardiner, V. V. Lissianski, Z. Qin, GRI-Mech 3.0, accessed on 27/01/2020. URL: http://www.me.berkeley.edu/gri_mech/.

[46] J. Koop, O. Deutschmann, Detailed surface reaction mechanism for Pt- 
catalyzed abatement of automotive exhaust gases, Applied Catalysis B: Environmental 91 (2009) 47-58. doi:10.1016/j .apcatb.2009.05.006.

[47] Y. K. Park, P. Aghalayam, D. G. Vlachos, A Generalized Approach for Predicting Coverage-Dependent Reaction Parameters of Complex Surface Reactions: Application to $\mathrm{H}_{2}$ Oxidation over Platinum, Journal of Physical Chemistry A 103 (1999) 8101-8107. doi:10.1021/jp9916485.

[48] N. Mladenov, J. Koop, S. Tischer, O. Deutschmann, Modeling of transport and chemistry in channel flows of automotive catalytic converters, Chemical Engineering Science 65 (2010) 812 - 826. doi:10.1016/j . ces . 2009.09 .034$.

[49] E. Kladopoulou, S. Yang, J. Johnson, G. Parker, A. G. Konstandopoulos, A study describing the performance of diesel particulate filters during loading and regeneration: A lumped parameter model for control applications, SAE transactions 112 (2003) 647-668. doi:10.4271/ 2003-01-0842.

[50] S. J. Lee, S. J. Jeong, W. S. Kim, Numerical design of the diesel particulate filter for optimum thermal performances during regeneration, Applied Energy 86 (2009) 1124-1135. doi:10.1016/j.apenergy. 2008. 07.002 .

[51] J. Neeft, Kinetics of the oxidation of diesel soot, Fuel 76 (1997) 11291136. doi:10.1016/S0016-2361 (97)00119-1.

[52] A. G. Konstandopoulos, M. Kostoglou, Reciprocating flow regeneration 
of soot filters, Combustion and Flame 121 (2000) 488-500. doi:10.1016/ S0010-2180 (99) 00156-X.

[53] M. Schejbal, J. Štěpánek, M. Marek, P. Kočí, M. Kubíček, Modelling of soot oxidation by $\mathrm{NO}_{2}$ in various types of diesel particulate filters, Fuel 89 (2010) 2365-2375. doi:10.1016/j.fuel.2010.04.018.

[54] O. A. Haralampous, G. C. Koltsakis, Back-diffusion modeling of $\mathrm{NO}_{2}$ in catalyzed diesel particulate filters, Industrial \& Engineering Chemistry Research 43 (2004) 875-883. doi:10.1021/ie034187p.

[55] CMCL Innovations, SRM Engine Suite, 2019.

[56] A. Bhave, M. Kraft, Partially stirred reactor model: Analytical solutions and numerical convergence study of a pdf/monte carlo method, SIAM Journal on Scientific Computing 25 (2004) 1798-1823. doi:10. $1137 /$ S1064827502411328.

[57] A. Bhave, M. Balthasar, M. Kraft, F. Mauss, Analysis of a natural gas fuelled homogeneous charge compression ignition engine with exhaust gas recirculation using a stochastic reactor model, International Journal of Engine Research 5 (2004) 93-104. doi:10 . 1243/146808704772914273.

[58] A. Bhave, M. Kraft, L. Montorsi, F. Mauss, Sources of CO emissions in an HCCI engine: A numerical analysis, Combustion and Flame 144 (2006) 634-637. doi:10.1016/j. combustflame.2005.10.015.

[59] J. Etheridge, S. Mosbach, M. Kraft, H. Wu, N. Collings, Modelling soot formation in a DISI engine, Proceedings of the Combustion Institute 33 (2011) 3159-3167. doi:10.1016/j.proci.2010.07.039. 
[60] B. Wang, S. Mosbach, S. Schmutzhard, S. Shuai, Y. Huang, M. Kraft, Modelling soot formation from wall films in a gasoline direct injection engine using a detailed population balance model, Applied Energy 163 (2016) 154-166. doi:10.1016/j .apenergy.2015.11.011.

[61] M. Kraft, Stochastic modeling of turbulent reacting flow in chemical engineering, 1998.

[62] M. Kraft, P. Maigaard, F. Mauss, M. Christensen, B. Johansson, Investigation of combustion emissions in a homogeneous charge compression injection engine: Measurements and a new computational model, Proceedings of the Combustion Institute 28 (2000) 1195 - 1201. doi:10 . 1016/S0082-0784(00)80330-6.

[63] M. Balthasar, F. Mauss, A. Knobel, M. Kraft, Detailed modeling of soot formation in a partially stirred plug flow reactor, Combustion and Flame 128 (2002) 395 - 409. doi:10.1016/S0010-2180(01) 00344-3.

[64] P. Maigaard, F. Mauss, M. Kraft, Homogeneous charge compression ignition engine: A simulation study on the effects of inhomogeneities, Journal of Engineering for Gas Turbines and Power 125 (2003) 466 471. doi:10.1115/1.1563240.

[65] S. Mosbach, H. Su, M. Kraft, A. Bhave, F. Mauss, Z. Wang, J.-X. Wang, Dual injection homogeneous charge compression ignition engine simulation using a stochastic reactor model, International Journal of Engine Research 8 (2007) 41-50. doi:10.1243/14680874JER01806. 
[66] S. Mosbach, M. S. Celnik, A. Raj, M. Kraft, H. R. Zhang, S. Kubo, K.-O. Kim, Towards a detailed soot model for internal combustion engines, Combustion and Flame 156 (2009) 1156 - 1165. doi:10.1016/ j.combustflame.2009.01.003.

[67] N. Morgan, A. Smallbone, A. Bhave, M. Kraft, R. Cracknell, G. Kalghatgi, Mapping surrogate gasoline compositions into ron/mon space, Combustion and Flame 157 (2010) 1122 - 1131. doi:10.1016/j . combustflame.2010.02.003.

[68] J. Gao, H. Chen, G. Tian, C. Ma, F. Zhu, An analysis of energy flow in a turbocharged diesel engine of a heavy truck and potentials of improving fuel economy and reducing exhaust emissions, Energy Conversion and Management 184 (2019) 456-465. doi:10.1016/j.enconman.2019.01. 053.

[69] F. Payri, P. Olmeda, F. J. Arnau, A. Dombrovsky, L. Smith, External heat losses in small turbochargers: Model and experiments, Energy 71 (2014) 534-546. doi:10.1016/j .energy.2014.04.096.

[70] D. Fino, S. Bensaid, M. Piumetti, N. Russo, A review on the catalytic combustion of soot in Diesel particulate filters for automotive applications: From powder catalysts to structured reactors, Applied Catalysis A: General 509 (2016) 75-96. doi:10.1016/j .apcata.2015.10.016.

[71] M. Khosravi, A. Abedi, R. Hayes, W. Epling, M. Votsmeier, Kinetic modelling of pt and pt:pd diesel oxidation catalysts, Applied Catalysis 
B: Environmental 154-155 (2014) 16 - 26. doi:10.1016/j . apcatb. 2014. 02.001.

[72] C. P. Cho, Y. D. Pyo, J. Y. Jang, G. C. Kim, Y. J. Shin, NOx reduction and $\mathrm{N}_{2} \mathrm{O}$ emissions in a diesel engine exhaust using fe-zeolite and vanadium based scr catalysts, Applied Thermal Engineering 110 (2017) 18-24. doi:10.1016/j .applthermaleng. 2016.08.118.

[73] Z. Zhang, S. L. Yang, J. H. Johnson, Modeling and Numerical Simulation of Diesel Particulate Trap Performance During Loading and Regeneration, SAE Technical Paper (2002) 2002-01-1019. doi:10.4271/ 2002-01-1019.

[74] A. Suresh, A. Khan, J. H. Johnson, An Experimental and Modeling Study of Cordierite Traps - Pressure Drop and Permeability of Clean and Particulate Loaded Traps, SAE Technical Paper Series 2000 (2000). doi:10.4271/2000-01-0476.

[75] S. Yang, C. Deng, Y. Gao, Y. He, Diesel particulate filter design simulation: A review, Advances in Mechanical Engineering 8 (2016) 1-14. doi:10.1177/1687814016637328.

[76] J. C. Caroca, F. Millo, D. Vezza, T. Vlachos, A. De Filippo, S. Bensaid, N. Russo, D. Fino, Detailed Investigation on Soot Particle Size Distribution during DPF Regeneration, using Standard and Bio-Diesel Fuels, Industrial \& Engineering Chemistry Research 50 (2011) 26502658. doi:10.1021/ie1006799. 
[77] E. J. Bissett, Mathematical model of the thermal regeneration of a wallflow monolith diesel particulate filter, Chemical Engineering Science 39 (1984) 1233-1244. doi:10.1016/0009-2509 (84)85084-8.

[78] J. H. Kim, M. Y. Kim, H. G. Kim, $\mathrm{NO}_{2}$-assisted soot regeneration behavior in a diesel particulate filter with heavy-duty diesel exhaust gases, Numerical Heat Transfer, Part A: Applications 58 (2010) 725739. doi:10.1080/10407782.2010.523293.

[79] D. Zhang, H. Zhang, Y. Yan, Copper-ceria catalysts supported on NaX zeolite for CO oxidation, Microporous and Mesoporous Materials 243 (2017) 193-200. doi:10.1016/j.micromeso.2017.02.016.

[80] Directive 2004/26/EC of the European Parliament and of the Council of 21 April 2004 amending Directive 97/68/EC on the approximation of the laws of the Member States relating to measures against the emission of gaseous and particulate pollutants from internal combustion engines to be installed in non-road mobile machinery, 2004.

[81] D. Nurkowski, P. Buerger, J. Akroyd, M. Kraft, A detailed kinetic study of the thermal decomposition of tetraethoxysilane, Proceedings of the Combustion Institute 35 (2015) 2291-2298. doi:10.1016/j.proci. 2014.06 .093$. 